\title{
Absorption and Disposition of Coproporphyrin I (CPI) in Cynomolgus Monkeys and Mice: Pharmacokinetic Evidence to Support the Use of CPI to Inform the Potential for Organic Anion-Transporting Polypeptide Inhibition $\$$
}

\author{
Xiaomei Gu, Lifei Wang, Jinping Gan, R. Marcus Fancher, Yuan Tian, Yang Hong, Yurong Lai, \\ Michael Sinz, and Hong Shen
}

Departments of Metabolism and Pharmacokinetics (X.G., L.W., J.G., R.M.F., Y.L., M.S., H.S.) and Radiochemistry (Y.T., Y.H.), Bristol Myers Squibb Company, Princeton, New Jersey

Received January 28, 2020; accepted May 19, 2020

\begin{abstract}
Despite a recent expansion in the recognition of the potential utility of coproporphyrin (CP) as an endogenous biomarker of organic anion-transporting polypeptide (OATP) 1B activity, there have been few detailed studies of CP's pharmacokinetic behavior and an overall poor understanding of its pharmacokinetic fate from tissues and excretion. Here, we describe the pharmacokinetics of octadeuterium-labeled coproporphyrin I (CPI-d8) in cynomolgus monkeys following oral and intravenous administration. CPI-d8 has a half-life and bioavailability of 7.6 hours and $3.2 \%$, respectively. Cynomolgus monkeys received oral cyclosporin A (CsA) at 4, 20, and $100 \mathrm{mg} / \mathrm{kg}$ which yielded maximum blood concentrations $\left(C_{\max }\right)$ and area under the plasma concentration-time curve (AUC) values of $0.19,2.5$, and $3.8 \mu M$, and 2.7, 10.5, and $26.6 \mu M \cdot h$, respectively. The apparent CsA-dose dependent increase in the AUC ratio of CPI-d8 (1.8, 6.2, and 10.5), CPI (1.1, 1.4, and 4.4), and CPIII (1.1, 1.8, and 4.6) at 4,20 , and $100 \mathrm{mg}$, respectively. In contrast, the plasma concentrations of CPI and CPIII were generally not affected by intravenous administration of the renal organic anion and cation transporter inhibitors (probenecid and pyrimethamine, respectively). In addition,
\end{abstract}

tritium-labeled coproporphyrin I $\left(\left[^{3} \mathrm{H}\right] \mathrm{CPI}\right)$ showed specific and rapid distribution to the liver, intestine, and kidney after an intravenous dose in mice using quantitative whole-body autoradiography. Rifampin markedly reduced the liver and intestinal uptake of $\left[{ }^{3} \mathrm{H}\right] \mathrm{CPI}$ while increasing the kidney uptake. Taken together, these results suggest that hepatic OATP considerably affects the disposition of CPI in animal models, indicating CPI is a sensitive and selective endogenous biomarker of OATP inhibition.

\section{SIGNIFICANCE STATEMENT}

This study demonstrated that coproporphyrin I (CPI) has favorable oral absorption, distribution, and elimination profiles in monkeys and mice as an endogenous biomarker. It also demonstrated its sensitivity and selectivity as a probe of organic anion-transporting polypeptide (OATP) 1B activity. The study reports, for the first time, in vivo pharmacokinetics, tissue distribution, sensitivity, and selectivity of CPI as an OATP1B endogenous biomarker in animals. The data provide preclinical support for exploration of its utility as a sensitive and selective circulating OATP biomarker in humans.

\section{Introduction}

Although most of the observed drug-drug interactions (DDIs) are caused by CYP3A inhibition and induction when developing a new drug, drug transporters also play an important role in drug interactions. Either alone or with a drug-metabolizing enzyme, they mediate approximately half of all DDIs characterized in the package inserts of 34 new small molecule drugs that were approved by the US

This study is supported by Bristol Myers Squibb Company.

https://doi.org/10.1124/dmd.120.090670.

S This article has supplemental material available at dmd.aspetjournals.org.
Food and Drug Administration in 2017 (Yu et al., 2019). Moreover, hepatic organic anion-transporting polypeptide (OATP) 1B1 and OATP1B3 mediated more than half of the DDIs with area under the plasma-time curve fold change (AUCR) greater than or equal to 5 (Yu et al., 2019). In agreement, the OATP/Oatp transporters are the most abundant transporter proteins, accounting for $29 \%-69 \%$ of total drug transporter proteins in the liver across species (Wang et al., 2015). Furthermore, the observed individual and interethnic variability in OATP1B1 transport activity has been demonstrated to be a cause of variability in pharmacokinetics, efficacy and safety of OATP1B drug substrates (Marzolini et al., 2004; Konig et al., 2006; Link et al., 2008;

ABBREVIATIONS: $\left[{ }^{3} \mathrm{H}\right] \mathrm{CPI}$, tritium-labeled coproporphyrin I; AUC, area under the plasma concentration-time curve; $\mathrm{AUC}_{0-24} \mathrm{~h}$, area under the plasma concentration-time curve from 0 to 24 hours; AUCR, area under the plasma-time curve fold change; $A_{U C} C_{T O T}$, area under the plasma concentration-time curve from zero to infinity; $C L_{\text {TOT }}$, total plasma clearance; $\mathrm{CP}$, coproporphyrin; $\mathrm{CPI}$-d8, octadeuterium-labeled coproporphyrin I; CsA, cyclosporin A; DDI, drug-drug interaction; FSM, furosemide; $I C_{50}$, concentration required to inhibit transport by $50 \%$; LC-MS/MS, liquid chromatography-tandem mass spectrometry; MATE, multidrug and toxin extrusion protein; MFM, metformin; m/z, mass-to-charge ratio; NTCP, sodium taurocholate cotransporting polypeptide; OAT, organic anion transporter; OATP, organic anion-transporting polypeptide; OCT2, organic cation transporter 2; PO, oral; PROB, probenecid; PYR, pyrimethamine; QWBA, quantitative whole-body autoradiography; RIF, rifampicin; UPLC, ultraperformance liquid chromatography; $V d_{\mathrm{SS}}$, volume of distribution at steady state. 
TABLE 1

Cynomolgus monkey CPI-d8 dosing and administration route groups

\begin{tabular}{lcccc}
\hline Group & Pretreatment & CPI-d8 Dose & $\begin{array}{c}\text { PI-d8 } \\
\text { Administration } \\
\text { Route }\end{array}$ & $\begin{array}{c}\text { Replicate } \\
(n)\end{array}$ \\
\hline 1 & None & $0.2 \mathrm{mg} / \mathrm{kg}$ & PO & 3 \\
2 & None & $0.1 \mathrm{mg} / \mathrm{kg}$ & i.v. & 3 \\
3 & $4 \mathrm{mg} / \mathrm{kg} \mathrm{CsA}$, PO & $0.1 \mathrm{mg} / \mathrm{kg}$ & i.v. & 3 \\
4 & i.v. & $6^{b}$ \\
5 & $20 \mathrm{mg} / \mathrm{kg} \mathrm{CsA}$, PO & $0.1 \mathrm{mg} / \mathrm{kg}$ & i.v. & 3 \\
6 & $100 \mathrm{mg} / \mathrm{kg} \mathrm{CsA}$, PO & $0.1 \mathrm{mg} / \mathrm{kg}$ & PO & 3 \\
\hline
\end{tabular}

${ }^{a}$ In the coadministration groups (i.e., groups 3, 4, 5, and 6), a CPI-d8 solution was administered to each monkey 60 minutes after CsA administration.

${ }^{b} \mathrm{~A}$ crossover study design was used, and the same three male cynomolgus monkeys were dosed over a series of six treatments with a 1-week washout between treatments $(n=3)$. One exception was the group 4 that was repeated because of a dosing mistake $(n=6)$.

Tomita et al., 2013). Consequently, the in vitro and in vivo approaches to assess the inhibition potential of a new drug toward OATP1B1 and OATP1B3 have been recommended and updated by the Food and Drug Administration (https://www.fda.gov/media/134582/download) and European Medicines Agency (https://www.ema.europa.eu/en/documents/ scientific-guideline/guideline-investigation-drug-interactions_en.pdf).

Transporter biomarker research is drawing increasing attention from the pharmaceutical industry, academia, and regulatory authorities because biomarkers allows for early identification, prediction, and clinical monitoring of a specific drug interaction, reflecting the transporter inhibition liability of a drug candidate (Chu et al., 2017; Mariappan et al., 2017; Chu et al., 2018; Muller et al., 2018; Rodrigues et al., 2018; Shen, 2018). Plasma coproporphyrin (CP) I and CPIII were recently identified as novel endogenous biomarkers of hepatic OATP transporter function in monkeys and mice (Shen et al., 2016a). The oral administration of $100 \mathrm{mg} / \mathrm{kg}$ cyclosporin A (CsA) and $15 \mathrm{mg} / \mathrm{kg}$ rifampicin (RIF), two known OATP inhibitors, significantly increased the areas under the plasma concentrationtime curves (AUCs) of CPI and CPIII by 2.6-5.2-fold in monkeys . These changes are in agreement with those of rosuvastatin in the same animals (2.6-5.2 fold vs. 2.9-6.3-fold)Shen et al., 2013, 2015). In addition, the plasma CPI and CPIII concentrations were markedly increased in Oatpla/ $1 \mathrm{~b}$ knockout mice compared with wild-type animals (7.1-18.4-fold), which were also in agreement with the increases in plasma rosuvastatin exposure (7.1-18.4-fold vs. 14.6-fold) (Shen et al., 2016a). Consequently, the clinical studies that assessed the dynamic changes and utility of plasma $\mathrm{CP}$ as an initial in vivo evaluation of weak to strong OATP1B1 and OATP1B3 inhibition were performed by different groups in the pharmaceutical industry and academia (Lai et al., 2016; Kunze et al., 2018a; Liu et al., 2018; Shen et al., 2018a; Takehara et al., 2018; Yee et al., 2019). The evaluation of CPI and CPIII as endogenous biomarkers of OATP1B inhibition in humans by quantitative scoring and prediction were demonstrated in those studies. CPI enabled in vivo assessment of inhibition potential of GDC-0810 toward OATP1B as early as phase I ascending dose studies during drug development (Cheung et al., 2019). This novel biomarker is less expensive than a dedicated DDI study with a clinical probe and benefits downstream clinical plans by optimizing the development plan and prioritizing clinical studies (Chu et al., 2018; Muller et al., 2018; Shen et al., 2018b). Moreover, it is envisioned that CP will be used jointly with modeling tools to overcome current limitation of transporter in vitro-to-in vivo extrapolation and greatly improve translational transporter-mediated DDI science (Wilson et al., 1988; Barnett et al., 2018; Yoshida et al., 2018; Yoshikado et al., 2018). To date, however, the pharmacokinetic characteristics including absorption, distribution, metabolism, and elimination of CPI and CPIII have not been studied. As endogenous substances that are subject to efficient biliary excretion, CPI and CPIII may also undergo enterohepatic recirculation. Therefore, understanding the oral absorption of CP is essentially important.
In addition, there have not been reports of the in vivo selectivity of $\mathrm{CP}$ as a hepatic OATP1B transporter substrates when compared with major renal drug transporters including organic anion transporter (OAT) 1, OAT3, organic cation transporter 2 (OCT2), multidrug and toxin extrusion protein (MATE) 1, and MATE2-K.

In recent years, the cynomolgus monkey has increasingly been used as an animal model to investigate clinical OATP1B-mediated inhibition by drugs such as RIF and CsA (Shen et al., 2013, 2015; Takahashi et al., 2016; Thakare et al., 2017; De Bruyn et al., 2018; Ufuk et al., 2018; Takahashi et al., 2019; Zhang et al., 2019). As described herein, the absorption, distribution, and elimination of CPI were characterized by using deuterium- and tritium-labeled CPI in cynomolgus monkeys and 57BL6 mice, respectively. The first key question we wanted to address in this study was if deuterium-labeled CPI would be extensively available after oral administration of CPI-d8. The bioavailability of CPI in monkeys was determined by comparing the systemic exposures after a single dose of $0.1 \mathrm{mg} / \mathrm{kg} \mathrm{CPI-d8} \mathrm{i.v.} \mathrm{and} \mathrm{an} \mathrm{oral} \mathrm{(PO)} \mathrm{dose} \mathrm{of} 0.2 \mathrm{mg} / \mathrm{kg}$ $\mathrm{CPI}-\mathrm{d} 8$ in cynomolgus monkeys. Second, the volume of distribution at steady state, clearance, and elimination half-life were determined in monkeys after a single dose of $0.1 \mathrm{mg} / \mathrm{kg}$ CPI-d8 i.v. In addition, we were interested in investigating the extent of biodistribution of $\mathrm{CP}$ between blood, liver, kidney, and intestine by using quantitative whole-body autoradiography (QWBA) as this can differ and provide additional insights. Therefore, the tissue distribution was assessed in mice after a single i.v. dose of $0.04 \mathrm{mg} / \mathrm{kg}$ tritium-labeled coproporphyrin $\mathrm{I}\left(\left[{ }^{3} \mathrm{H}\right]\right.$ $\mathrm{CPI}$ ) alone and with RIF (PO, $100 \mathrm{mg} / \mathrm{kg}$ ) by QWBA. Lastly, for the sensitivity and selectivity of $\mathrm{CP}$ as an endogenous biomarker of hepatic OATP1B inhibition, an investigation was performed to analyze plasma $\mathrm{CPI}$ and CPIII concentrations in cynomolgus monkeys after single oral doses of CsA $(4,20$, and $100 \mathrm{mg} / \mathrm{kg})$. The highest dose of $100 \mathrm{mg} / \mathrm{kg}$ is selected because we previously reported that the systemic exposure after a single oral administration of $100 \mathrm{mg} / \mathrm{kg} \mathrm{CsA}$ oral solution (Neoral) in cynomolgus monkeys was comparable to that at steady state after multiple doses in patients (Shen et al., 2013). In addition, animals also received a single dose of $0.1 \mathrm{mg} / \mathrm{kg}$ CPI-d8 i.v. to ensure that OATP1B was inhibited by CsA in a dose-dependent manner and allow comparison between endo- and exogenous probes. Moreover, an attempt was made to demonstrate $\mathrm{CP}$ as a selective biomarker for OATP1B inhibition by profiling CPI and CPIII in monkeys after single intravenous doses of probenecid (PROB), a potent inhibitor of OAT1/3, or pyrimethamine (PYR), a potent inhibitor of OCT2 and MATE1/2-K.

\section{Materials and Methods}

\section{Chemicals and Reagents}

CPI-d8, CPIII-d8, and $\left[{ }^{3} \mathrm{H}\right] \mathrm{CPI}(4.9 \mathrm{Ci} / \mathrm{mmol} ;>97.5 \%$ purity $)$ were synthesized by Bristol Myers Squibb (Princeton, NJ) (Supplemental Fig. 1, A-C). CPI and 
TABLE 2

Mean pharmacokinetic parameters of CPI-d8 in cynomolgus monkeys after a single 10-minute intravenous infusion of $0.1 \mathrm{mg} / \mathrm{kg}$ CPI-d8 alone, a single oral dose of $0.2 \mathrm{mg} / \mathrm{kg}$ CPI-d8 alone, and combination of CsA (PO, $100 \mathrm{mg} / \mathrm{kg}$ ) with CPI-d8

Data are presented as means \pm S.D. ( $\mathrm{n}=3$ monkeys). CPI-d8 was administered 60 minutes after CsA administration (PO, $100 \mathrm{mg} / \mathrm{kg})$. The pharmacokinetic parameters were determined as indicated under Materials and Methods. Statistics were conducted by two-sided paired Student's t test.

\begin{tabular}{|c|c|c|c|c|}
\hline \multirow{2}{*}{ Pharmacokinetic parameter } & \multicolumn{2}{|c|}{ Intravenous } & \multicolumn{2}{|c|}{ Oral } \\
\hline & CPI-d8 alone & With CsA & CPI-d8 alone & With CsA \\
\hline$C_{\max }(\mathrm{nM})$ & NA & NA & $1.1 \pm 0.5$ & $7.2 \pm 7.5$ \\
\hline$T_{\max }(\mathrm{h})$ & NA & NA & $1.5 \pm 1.3$ & $0.3 \pm 0.4$ \\
\hline $\mathrm{AUC}_{0-24 \mathrm{~h}}(\mathrm{nM} \bullet \mathrm{h})$ & $188 \pm 31.4$ & $2102 \pm 1645^{*}$ & $9.8 \pm 3.0$ & $21.1 \pm 8.3$ \\
\hline $\mathrm{AUC}_{\text {TOT }}(\mathrm{nM} \bullet \mathrm{h})$ & $189 \pm 31.5$ & $2128 \pm 1686^{*}$ & $11.5 \pm 3.4$ & $25.0 \pm 7.2$ \\
\hline$V d_{\mathrm{SS}}(1 / \mathrm{kg})$ & $0.57 \pm 0.10$ & $0.24 \pm 0.13 * *$ & NA & NA \\
\hline$C L_{\mathrm{TOT}}(\mathrm{ml} / \mathrm{min}$ per kilogram $)$ & $10.1 \pm 1.7$ & $1.3 \pm 0.9 * *$ & NA & NA \\
\hline$T_{1 / 2}(\mathrm{~h})$ & $7.6 \pm 0.5$ & $3.3 \pm 1.1 *$ & $11.2 \pm 4.6$ & $8.6 \pm 3.1$ \\
\hline$F(\%)$ & NA & NA & $3.2 \pm 1.7$ & $0.8 \pm 0.6$ \\
\hline
\end{tabular}

NA, not applicable.

${ }^{*} P<0.05 ; * * P<0.01$ compared with the CsA alone administration group.

CPIII were purchased from Frontier Scientific, Inc. (Logan, UT). CsA, CsA- ${ }^{13} \mathrm{C}_{2}$, d4, RIF, PROB, PYR, and CPI- ${ }^{15} \mathrm{~N}_{4}$ were purchased from Toronto Research Chemicals (Toronto, ON, Canada). High-performance liquid chromatography grade methanol, acetonitrile, and water were obtained from Fisher Scientific (Fair Lawn, NJ). Formic acid and hydrochloric acid were obtained from EMD Chemicals Inc. (Gibbstown, NJ). CsA oral solution (Neoral, $100 \mathrm{mg} / \mathrm{ml}$ ) was obtained from Novartis Pharmaceuticals (East Hanover, NJ). Cynomolgus monkey and human plasma that were stripped three times with charcoal were purchased from Bioreclamation IVT (Westbury, NY).

\section{Pharmacokinetics Studies Employing Cynomolgus Monkeys and C57BL6} Mice

All animal experiments were performed at the Bristol Myers Squibb animal facility in accordance to the National Institutes of Health guidelines and were approved by the Bristol Myers Squibb Institutional Animal Care and Use Committee. Animals were housed in a temperature-controlled environment at $64-84^{\circ} \mathrm{F}, 30 \%-70 \%$ humidity, and a 12 -hour light-dark cycle.

Bioavailability of CPI-d8 and Effect of CsA Administration on Disposition of CPs in Monkeys. A crossover study design was used and the same three male cynomolgus monkeys (5.3-6.3 kg body weight) were dosed over a series of six treatments indicated in Table 1 with a 1-week washout between treatments.

Monkeys were fasted for 12 hours before each oral dose but not the intravenous dose of CPI-d8 or CsA. Water was made available ad libitum and a daily ration of food was provided approximately 4 hours postdose during the study. CsA oral solution (Neoral) was given via oral gavage at 0 (blank vehicle), 4, 20, and $100 \mathrm{mg} / \mathrm{kg}(5 \mathrm{ml} / \mathrm{kg}$ ) (Table 1). Sixty minutes after the oral CsA administration, CPI-d8 was given by an oral administration at dose of $0.2 \mathrm{mg} / \mathrm{kg}[5 \mathrm{ml} / \mathrm{kg}$; $5 \%$ DMSO and $95 \%$ water $(\mathrm{v} / \mathrm{v})]$ or an intravenous infusion via a femoral vein at dose of $0.1 \mathrm{mg} / \mathrm{kg}$ [1 ml/kg; $2 \%$ DMSO and $98 \%$ water (v/v)] over 10 minutes. Approximately $500 \mu \mathrm{l}$ serial blood samples were collected in EDTAanticoagulant via the cephalic or saphenous veins just before administration and at 0.17 (i.v.), 0.25, 0.5, 0.75, 1, 2, 3, 5, 7, and 24 hours after CPI-d8 dosing. Fifty microliters of whole blood was aliquoted and transferred to tubes containing $450 \mu 1$ of $50 \%$ methanol and $50 \%$ acetonitrile $(\mathrm{v} / \mathrm{v})$. The tubes were vortexed for a minimum of 20 seconds and the mixture were stored at $-70^{\circ} \mathrm{C}$ for CsA analysis. The remaining blood samples were centrifuged at $3000 \mathrm{~g}$ for 10 minutes at $2-8^{\circ} \mathrm{C}$ within 1 hour of collection to generate plasma, and the samples were stored frozen at $-70^{\circ} \mathrm{C}$ until $\mathrm{CPI}-\mathrm{d} 8, \mathrm{CPI}$, and CPIII analysis. Urine was collected at intervals of 0-7 and 7-24 hours after administration of CPI-d8 using metabolism cages and stored at $-70^{\circ} \mathrm{C}$ until analysis.

Effect of PROB and Furosemide Administration on Disposition of CPs in Monkeys. Plasma and urine samples were obtained from the pharmacokinetic interaction study between PROB and furosemide (FSM) in cynomolgus monkeys conducted previously (Shen et al., 2018c). Briefly, the samples were collected after intravenous administration of $2 \mathrm{mg} / \mathrm{kg}$ FSM alone, $40 \mathrm{mg} / \mathrm{kg}$ PROB alone, and coadministration of PROB or FSM, three-period crossover pharmacokinetic DDI study. In the third period, FSM was given to animals 30 minutes after PROB administration. Plasma samples before and $0.08,0.17,0.25,0.5,0.75,1,2,3,5,7$, and 24 hours after the start of the FSM infusion were collected and stored at $-70^{\circ} \mathrm{C}$ until analysis.

Effect of PYR Administration on Disposition of CPs in Monkeys. Plasma and urine samples were obtained from the pharmacokinetic interaction study between PYR and metformin (MFM) in cynomolgus monkeys conducted previously (Shen et al., 2016b). Briefly, the samples were collected after intravenous administration of $3.9 \mathrm{mg} / \mathrm{kg}$ MFM alone and coadministration of PYR $(0.5 \mathrm{mg} / \mathrm{kg}$; i.v. $)$ and MFM ( $3.9 \mathrm{mg} / \mathrm{kg}$; i.v.). In the coadministration period, MFM was given to animals 60 minutes after PYR administration. Plasma samples before and $0.25,0.5,0.75,1,2,3,5,7,24$, and 48 hours after start of the MFM

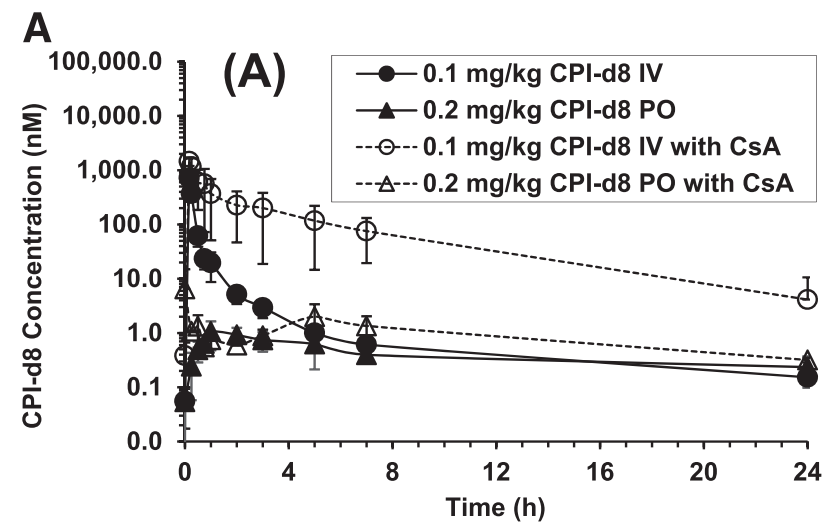

B

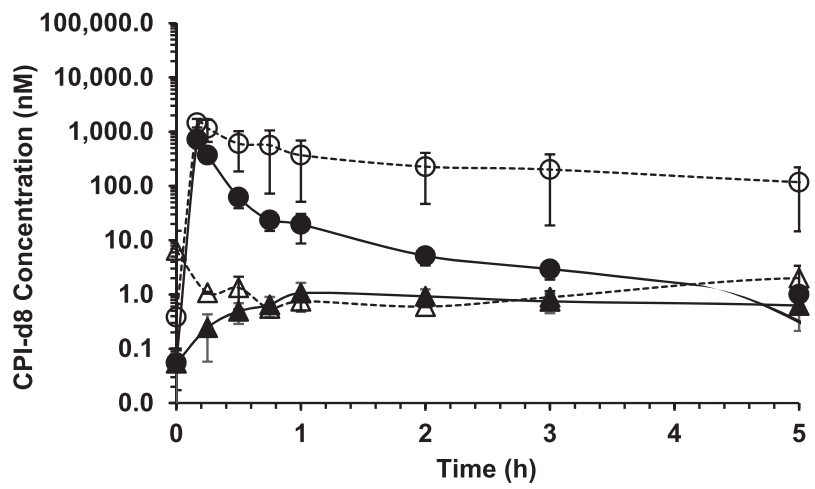

Fig. 1. Plasma concentration of CPI-d8 from 0 to 24 (A) and 0 to 5 hours (B) in cynomolgus monkeys $(n=3)$ after intravenous infusion of $0.1 \mathrm{mg} / \mathrm{kg}$ CPI-d8 for 10 minutes and oral administration of $0.2 \mathrm{mg} / \mathrm{kg}$ CPI-d8 alone or in combination with CsA (PO, $100 \mathrm{mg} / \mathrm{kg}$ ). In the coadministration groups, a CPI-d8 solution was administered to each animal 60 minutes after CsA administration. Data are expressed as means \pm S.D. 

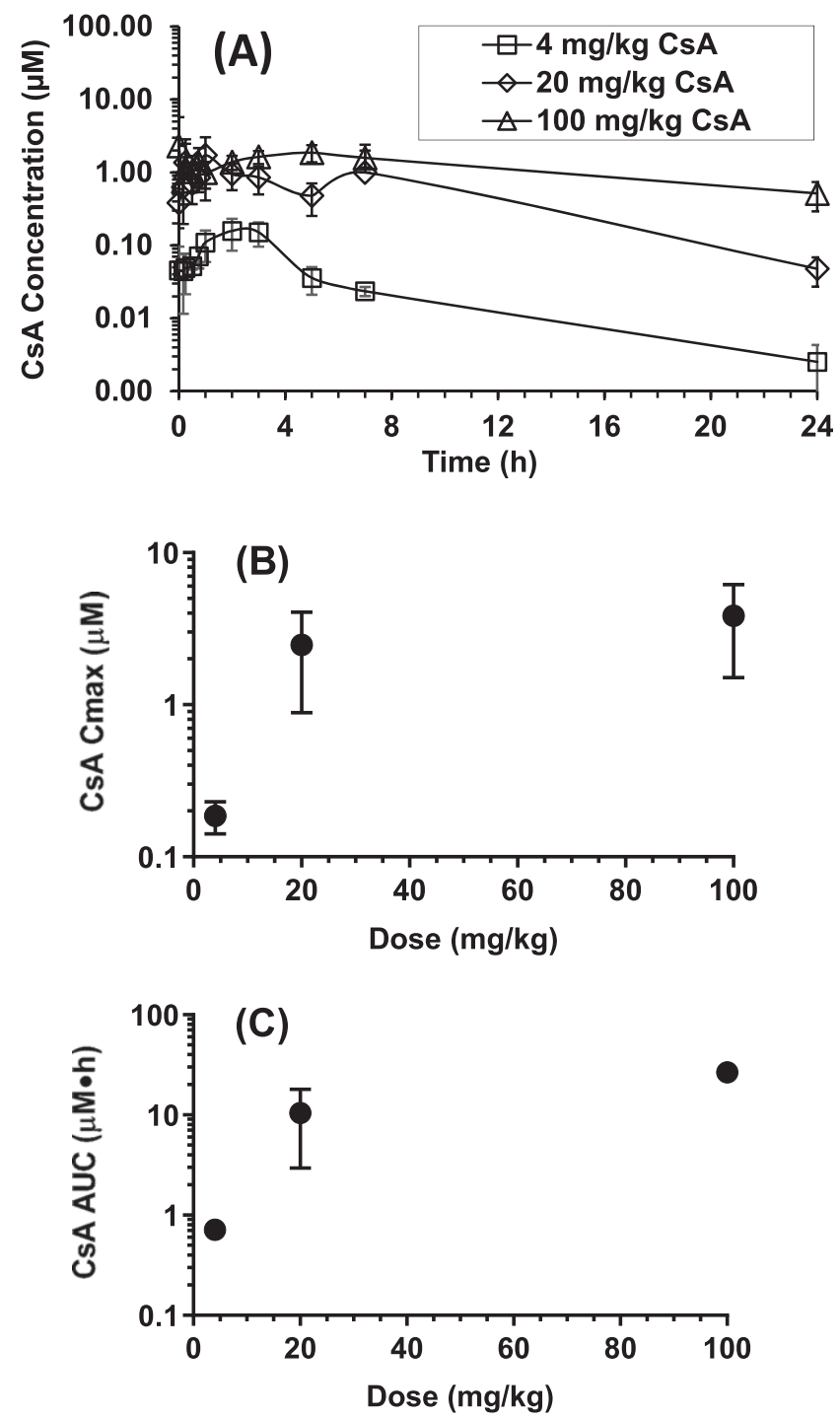

Fig. 2. Plasma concentration (A), $C_{\max }$ (B), and AUC (C) of CsA in cynomolgus monkeys $(n=3)$ after oral drug administration at different doses: 4, 20, and $100 \mathrm{mg} / \mathrm{kg}$. Data are expressed as means \pm S.D.

infusion were collected and stored at $-70^{\circ} \mathrm{C}$ until analysis. However, the plasma $\mathrm{CP}$ levels were analyzed at 1,5 , and 24 hours only due to availability of the plasma samples left from the original study. The mean concentrations of PYR at 1,5, and 24 hours postdose are 537, 567, and $174 \mathrm{nM}$, respectively (Shen et al., 2016b).

Effect of RIF Administration on Tissue Distribution of $\left[{ }^{3} \mathrm{H}\right] \mathrm{CPI}$ as Determined by QWBA in Mice. C57BL6 mice, 8-10 weeks old, weighing from 17 to $21 \mathrm{~g}$ were obtained from Charles River (Malvern, PA) and allowed to acclimate for at least 1 week before the start of the experiment. Eight mice were injected intravenously through the tail vein with $5 \mu \mathrm{l} / \mathrm{g}$ body weight at $8 \mu \mathrm{g} / \mathrm{ml}$, to give a final dose of $\left.0.04 \mathrm{mg} / \mathrm{kg} \mathrm{[}{ }^{3} \mathrm{H}\right] \mathrm{CPI}(5 \mathrm{mCi} / \mathrm{kg})(n=8)$. Additionally, eight animals were injected with $\left[{ }^{3} \mathrm{H}\right] \mathrm{CPI}$ plus RIF (PO, $100 \mathrm{mg} / \mathrm{kg}$ ), and a $\left[{ }^{3} \mathrm{H}\right] \mathrm{CPI}$ water solution was administered intravenously into mice 60 minutes after RIF administration. At the specified time after injection (2, 20 minutes, 3, or 24 hours), two mice from each group were euthanized by $\mathrm{CO}_{2}$ overexposure and were immediately frozen in a bath of hexane with dry ice. The biodistribution of $\left[{ }^{3} \mathrm{H}\right]$ CPI was determined by QWBA as described below.

Frozen carcasses were embedded in chilled $2 \%$ of carboxymethylcellulose (Sakura Finetek, Torrance, CA). The embedded blocks were stored at $-80^{\circ} \mathrm{C}$ until the time of sectioning to minimize diffusion of radiolabel materials into thawed tissues. Forty micrometer thick lengthwise whole-body sections were made by using a CM3600 (Leica microsystems, Nussloch, Germany). The sections used for autoradiography were left on the tape and placed on a $\left[{ }^{3} \mathrm{H}\right]$-sensitive phosphor imaging plate in a lead-shielded box at room temperature for 3 weeks. Afterward, the plate was scanned in a Typhoon FLA 7000 image acquisition system (GE Healthcare Bio-Sciences, Pittsburgh, PA). The concentrations of total radiolabeled material in the tissues were determined by comparative densitometry and autoradiogram digital analysis as described previously (Shen et al., 2016c). Blood samples containing known amounts of radiolabeled compound treated under similar conditions were used as calibrators. Data for the concentration of $\left[{ }^{3} \mathrm{H}\right] \mathrm{CPI}$ in the animal tissues and organs were normalized by the whole body weight, in grams (i.e., the $\mathrm{nCi}\left[{ }^{3} \mathrm{H}\right] \mathrm{CPI} / \mathrm{g}$ ).

\section{Analytical Methods}

Liquid Chromatography-Tandem Mass Spectrometry Analysis of CsA in Blood. Blood concentrations of CsA were measured by liquid chromatography-tandem mass spectrometry (LC-MS/MS) as described previously, with some modifications (Shen et al., 2015). Briefly, a Shimazdzu ultraperformance liquid chromatography (UPLC) system (Shimadzu Corporation, Columbian, MD) was coupled to a Sciex API-6500 tandem mass spectrometer with a turbo-electrospray ionization source (Applied Biosystems, MDS Sciex; Toronto, Canada). Chromatographic separations were performed using an Acquity UPLC BEH C18 column $(1.7 \mu \mathrm{m}, 100 \times 2.1 \mathrm{~mm})$ (Waters Corporation, Milford, MA) maintained at $60^{\circ} \mathrm{C}$. The mobile phase consisted of $0.1 \%$ formic acid in water (mobile phase A) and $0.1 \%$ formic acid in acetonitrile (mobile phase B), at a total flow rate of $0.7 \mathrm{ml} / \mathrm{min}$. The gradient profile was held at $25 \%$ mobile phase B for 0.5 minute, increased linearly to $100 \%$ in 2.5 minutes, held at $100 \%$ for 1.5 minutes, and finally brought back to $25 \%$ in 0.2 minute followed by 1.3 minutes' reequilibration (total run time of 6 minutes per sample). Quantitative data were acquired in multiple reaction monitoring, and the transitions used were as follows: mass-to-charge ratio $(\mathrm{m} / \mathrm{z}) 1219.5 \rightarrow \mathrm{m} / \mathrm{z} 1202.7$ for CsA and m/z $1225.5 \rightarrow \mathrm{m} / \mathrm{z}$ 1207.7 for $\mathrm{CsA}^{-13} \mathrm{C}_{2}$, d4.

Calibration curves were prepared in matrices by spiking $10 \mu \mathrm{l}$ of appropriate standard solution at final concentrations ranging from 1 to $2500 \mathrm{nM}$. For extraction of blood samples, $100 \mu \mathrm{l}$ of acetonitrile containing $400 \mathrm{nM} \mathrm{CsA}-{ }^{13} \mathrm{C}_{2}$, $\mathrm{d} 4$ as internal standard was added to $100 \mu \mathrm{l}$ of blood sample mixture. Samples were then vortex-mixed for 5 minutes, and the supernatants were transferred to a $0.45-\mu \mathrm{m}$ multiscreen hydrophilic filtration plate (Millipore, MA). After centrifugation at room temperature, filtrate of each sample was collected in a 96-well plate. A 5- $\mu \mathrm{l}$ aliquot was injected for analysis by LC-MS/MS.

LC-MS/MS Analysis of CPI-d8, CPI, and CPIII in Plasma and Urine. The LC-MS/MS analysis of CPI-d8, CPI, and CPIII was performed as described

TABLE 3

Mean pharmacokinetic parameters of CsA in cynomolgus monkeys after a single oral dose of 4, 20, or $100 \mathrm{mg} / \mathrm{kg}$ CsA

Data are presented as means \pm S.D. ( $n=3,6$, and 6 monkeys at doses of 4,20 , and $100 \mathrm{mg} / \mathrm{kg}$, respectively). The pharmacokinetic parameters were determined as indicated under Materials and Methods. Statistics were conducted by one-way ANOVA followed by Dunnett's multiple comparison method.

\begin{tabular}{|c|c|c|c|}
\hline \multirow{2}{*}{ Pharmacokinetic parameters } & \multicolumn{3}{|c|}{ CsA dose } \\
\hline & $4 \mathrm{mg} / \mathrm{kg}(n=3)$ & $20 \mathrm{mg} / \mathrm{kg}(n=6)$ & $100 \mathrm{mg} / \mathrm{kg}(n=6)$ \\
\hline Blood $\mathrm{AUC}_{0-24 \mathrm{~h}}(\mu \mathrm{M} \bullet \mathrm{h})$ & $2.7 \pm 0.6$ & $10.5 \pm 7.5$ & $26.6 \pm 4.1^{* * * ;} ; £$ \\
\hline Blood $C_{\max }(\mu \mathrm{M})$ & $0.19 \pm 0.04$ & $2.5 \pm 1.6^{*}$ & $3.8 \pm 2.3^{*}$ \\
\hline$T_{\max }(\mathrm{h})$ & $2.7 \pm 0.6$ & $2.3 \pm 2.5$ & $4.0 \pm 1.7$ \\
\hline$T_{1 / 2}(\mathrm{~h})$ & $5.2 \pm 1.6$ & $6.2 \pm 1.7$ & $9.1 \pm 2.0 *$ \\
\hline
\end{tabular}

${ }^{*} P<0.05 ; * * * P<0.001$ compared with the $4 \mathrm{mg} / \mathrm{kg}$ CsA group; ${ }^{\circledR} P<0.05$ compared with the $20 \mathrm{mg} / \mathrm{kg}$ CsA group. 
previously, with some modifications (Lai et al., 2016; Kandoussi et al., 2018). Briefly, a Shimazdzu UPLC system (Shimadzu Corporation) was coupled to a Sciex API-6500 tandem mass spectrometer with a turbo-electrospray ionization source (Applied Biosystems, MDS Sciex). The chromatographic separations were performed on a Waters Acquity UPLC BEH C18 column $(1.7 \mu \mathrm{m}, 100 \times 2.1 \mathrm{~mm})$ from Waters Corporation maintained at $65^{\circ} \mathrm{C}$. The mobile phase consisted of $0.1 \%$ formic acid in water (A) and $0.1 \%$ formic acid in acetonitrile (B), which was delivered at a flow rate of $0.6 \mathrm{ml} / \mathrm{min}$. The gradient profile was held at $28 \%$ mobile phase B for 0.5 minute, increased linearly to $40 \%$ in 3.5 minutes, and then increased linearly to $95 \%$ in 0.5 minute, held at $95 \%$ for 1 minute, and finally brought back to $28 \%$ in 0.5 minute followed by 1.0 -minute re-equilibration, resulting in total run time of 7 minutes per sample. Quantitative data were acquired in multiple reaction monitoring-positive ionization mode. CP-d8, CP, and CPI $-{ }^{15} \mathrm{~N}_{4}$ were detected at the selected reaction monitoring transitions of $\mathrm{m} / \mathrm{z}$ $655.3 \rightarrow \mathrm{m} / \mathrm{z} 596.3, \mathrm{~m} / \mathrm{z} \quad 663.3 \rightarrow \mathrm{m} / \mathrm{z} \quad 602.3$, and $\mathrm{m} / \mathrm{z} \quad 659.3 \rightarrow \mathrm{m} / \mathrm{z} \quad 600.3$, respectively. Calibration curves were prepared in blank plasma and urine stripped with charcoal at concentrations ranging from 0.1 to 500 and 0.2 to $1000 \mathrm{nM}$ for $\mathrm{CP}$ and $\mathrm{CP}-\mathrm{d} 8$, respectively.

The plasma and urine samples were extracted by using protein precipitation. Specifically, the $100 \mu \mathrm{l}$ plasma and urine samples were mixed with $600 \mu \mathrm{l}$ of icecold ethyl acetate containing $100 \mathrm{nM} \mathrm{CPI}-{ }^{15} \mathrm{~N}_{4}$ and $200 \mathrm{nM}$ CPIII-d8 (internal standard), followed by vortex mixing on a mixer for 5 minutes at room temperature. The mixed solutions were then centrifuged at $4000 \mathrm{rpm}$ for 15 minutes (Centrifuge model 5810R; Eppendorf), and the 400- $\mu$ l supernatants were aspirated and evaporated. Samples were then reconstituted in $50 \mu l$ of $1 \mathrm{M}$ formic acid solution. Five microliters of sample was injected for analysis.

\section{Pharmacokinetic and Statistical Data Analysis}

Phoenix WinNonlin 8.1 software (CERTRA, Princeton, NJ) was used for analysis of pharmacokinetic parameters of CPI-d8, CsA, CPI, and CPIII, following administration of probe with or without coadministration of transporter inhibitors. The area under the plasma concentration-time curve from 0 to 24 hours $\left(\mathrm{AUC}_{0-24 \mathrm{~h}}\right)$ was calculated using mixed trapezoidal method, whereas the area under the plasma concentration-time curve from zero to infinity $\left(\mathrm{AUC}_{\mathrm{TOT}}\right)$ includes $\mathrm{AUC}_{0-24 \mathrm{~h}}$ and that extrapolated from the last time point to infinity. The total plasma clearance $\left(C L_{\mathrm{TOT}}\right)$ was described by eq. 1 :

$$
C L_{\mathrm{TOT}}=\frac{\text { Dose }_{\mathrm{IV}}}{A U C_{\mathrm{TOT}}}
$$

The volume of distribution at steady state $\left(V d_{\mathrm{SS}}\right)$ was calculated by using the equation described as following:

$$
V d_{\mathrm{SS}}=\frac{\text { Dose }_{\mathrm{IV}} \times(A U M C)}{(A U C)^{2}}
$$

where $A U M C$ is the area under the curve of the first moment of the concentration-time curve. The eq. 3 was used to estimate the oral bioavailability $(F)$ :

$$
F=\frac{\operatorname{Dose}_{\mathrm{PO}} \times A U C_{\mathrm{IV}}}{\operatorname{Dose}_{\mathrm{IV}} \times A U C_{\mathrm{PO}}}
$$

To analyze the statistically significant difference in the pharmacokinetic parameters of CPI-d8 between two sets of data in monkeys, a two-sided paired Student's $t$ test was used because of the crossover design. One-way analysis of variance (ANOVA) was performed to assess CsA dose response by analyzing statistically significant differences in the pharmacokinetic parameters of CsA, CPI-d8, CPI, and CPIII among multiple CsA dose groups in monkeys. One-way ANOVA was also performed to evaluate the effect of $\mathrm{PROB}$ on $\mathrm{CP}$ systemic exposure by analyzing statistically significant differences in the pharmacokinetic parameters of CPI and CPIII among the administration of FSM alone, PROB alone, and PROB with FSM in monkeys. When a ratio showed that there were significant differences among CsA doses, the Dunnett method of multiple comparisons was used to determine which treatments differ. All statistical analyses were performed using Prism version 7.0 (GraphPad Software, Inc., San Diego, CA). A $P$ value of less than 0.05 was considered to be statistically significant $(* P<$ $0.05, * * P<0.01$, and $* * * P<0.001)$.

\section{Results}

Pharmacokinetics of CPI-d8 in Monkeys. The mean plasma concentrations of CPI-d8, measured by LC/MS-MS, following a single dose of CPI-d8 alone or coadministration of CsA (PO, $100 \mathrm{mg} / \mathrm{kg}$ ) in cynomolgus monkeys are summarized in Table 2 , and the corresponding plasma concentration-versus-time data are illustrated graphically in Figure 1. After intravenous administration of CPI-d8 alone, during the first 2 to 3 hours after stopping the infusion, there was a rapid drop in plasma concentration followed by a slower elimination phase, exhibiting a multiexponential decline (Fig. 1). The $C L_{\mathrm{TOT}}$ of CPI-d8 was $10.1 \pm$
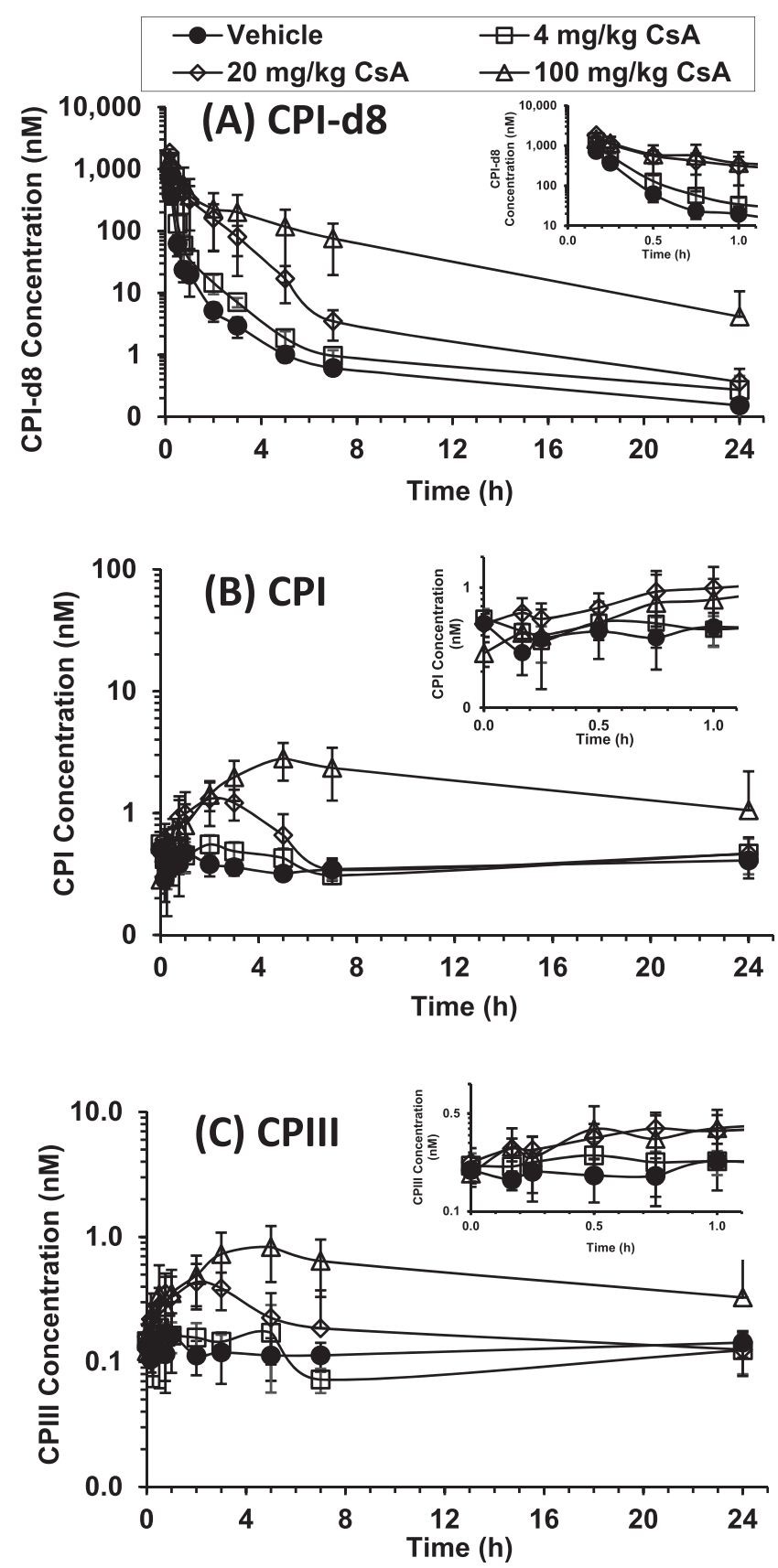

Fig. 3. Plasma concentrations of CPI (A), CPIII (B), and CPI-d8 (C) over time in cynomolgus monkeys $(n=3)$ after a single intravenous dose of $0.1 \mathrm{mg} / \mathrm{kg} \mathrm{CPI}-\mathrm{d} 8$ with and without CsA given as an oral dose of 4,20 , or $100 \mathrm{mg} / \mathrm{kg}$. In the coadministration groups, a CPI-d8 solution $(0.1 \mathrm{mg} / \mathrm{kg})$ was administered orally to each monkey 60 minutes after CsA administration $(100 \mathrm{mg} / \mathrm{kg}$; PO). Data are expressed as means \pm S.D. Inset depicts the same data from 0 to 1 hour. 
TABLE 4

Mean systemic exposures of $\mathrm{CP}$ in cynomolgus monkeys after a single 10-minute infusion of CPI-d8 $(0.1 \mathrm{mg} / \mathrm{kg})$ with increasing doses of CsA (PO, 4, 20, and $100 \mathrm{mg} / \mathrm{kg}$ )

Data are presented as means \pm S.D. The pharmacokinetic parameters were determined as indicated under Materials and Methods. AUCR and $C_{\text {max }} \mathrm{R}$ of $\mathrm{CP}$ dosed with CsA compared with vehicle control. Statistics were conducted by one-way ANOVA followed by Dunnett's multiple comparison method.

\begin{tabular}{|c|c|c|c|c|c|}
\hline \multirow{2}{*}{ Analyte } & \multirow{2}{*}{ Pharmacokinetic parameters } & \multicolumn{4}{|c|}{ Oral CsA dose } \\
\hline & & Vehicle & $4 \mathrm{mg} / \mathrm{kg}$ & $20 \mathrm{mg} / \mathrm{kg}$ & $100 \mathrm{mg} / \mathrm{kg}$ \\
\hline \multirow[t]{2}{*}{ CPI-d $8^{a}$} & $\mathrm{AUC}_{0-24 \text { h }}(\mathrm{nM} \bullet \mathrm{h})$ & $188 \pm 31.4$ & $345 \pm 88 * *$ & $1142 \pm 432^{* *}$ & $2102 \pm 1645^{*}$ \\
\hline & AUCR & 1.0 & $1.8 \pm 0.3^{* *}$ & $6.2 \pm 2.5^{* *}$ & $10.5 \pm 6.8^{*}$ \\
\hline \multirow[t]{4}{*}{$\mathrm{CPI}^{b}$} & $\mathrm{AUC}_{0-24 \mathrm{~h}}(\mathrm{nM} \bullet \mathrm{h})$ & $8.9 \pm 0.7$ & $9.7 \pm 1.9$ & $12.7 \pm 3.2$ & $39.6 \pm 21.0 *$ \\
\hline & AUCR & 1.0 & $1.1 \pm 0.3$ & $1.4 \pm 0.3^{*}$ & $4.4 \pm 2.1 *$ \\
\hline & $C_{\max }(\mathrm{nM})$ & $0.58 \pm 0.11$ & $0.58 \pm 0.10$ & $1.47 \pm 0.46$ & $2.84 \pm 0.94$ \\
\hline & $C_{\max } R$ & 1.0 & $1.2 \pm 0.16$ & $3.0 \pm 0.9 * *$ & $5.8 \pm 1.9^{* *}$ \\
\hline \multirow[t]{4}{*}{$\mathrm{CPIII}^{b}$} & $\mathrm{AUC}_{0-24 \mathrm{~h}}(\mathrm{nM} \bullet \mathrm{h})$ & $3.0 \pm 0.6$ & $2.7 \pm 0.7$ & $4.6 \pm 2.5$ & $11.6 \pm 8.0$ \\
\hline & AUCR & 1.0 & $1.1 \pm 0.3$ & $1.8 \pm 0.9$ & $4.6 \pm 3.0$ \\
\hline & $C_{\max }(\mathrm{nM})$ & $0.19 \pm 0.07$ & $0.21 \pm 0.08$ & $0.48 \pm 0.16^{*}$ & $0.86 \pm 0.37 *$ \\
\hline & $C_{\max } R$ & 1.0 & $1.6 \pm 0.9$ & $3.8 \pm 1.7^{*}$ & $6.9 \pm 3.7^{*}$ \\
\hline
\end{tabular}

$C_{\max } \mathrm{R}$, fold change in $C_{\max }$

$a_{n=3,3,6}$, and 3 monkeys at doses of 0 (vehicle), 4, 20, and $100 \mathrm{mg} / \mathrm{kg}$, respectively.

${ }^{b} n=6,3,6$, and 6 monkeys at doses of 0 (vehicle), 4, 20, and $100 \mathrm{mg} / \mathrm{kg}$, respectively.

${ }^{*} P<0.05 ;{ }^{* *} P<0.01 ;{ }^{* * *} P<0.001$ compared with the vehicle group.

$1.7 \mathrm{ml} / \mathrm{min}$ per kilogram. There is no report about the CPI blood to plasma partition. If there is no notable red blood cell partitioning, the blood clearance is low compared with monkey hepatic blood flow (i.e., $44 \mathrm{ml} / \mathrm{min}$ per kilogram) (Davies and Morris, 1993). The $V d_{\mathrm{ss}}$ in monkeys was $0.57 \mathrm{l} / \mathrm{kg}$ (Table 2), indicating limited extravascular distribution. This $V d_{\mathrm{ss}}$ is similar to total body water (i.e., $0.7 \mathrm{l} / \mathrm{kg}$ ) (Davies and Morris, 1993). The $T_{1 / 2}$ was $7.6 \pm 0.5$ hours. A single oral dose of $100 \mathrm{mg} / \mathrm{kg} \mathrm{CsA}$ significantly increased the $\mathrm{AUC}_{0-24 \mathrm{~h}}\left(\mathrm{AUC}_{\mathrm{TOT}}\right.$ of CPI-d8 (approximately 10-fold) $(P<0.05)$ compared with CPI-d8 alone (Fig. 1; Table 2). The apparent $\mathrm{T}_{1 / 2}$ was significantly smaller in CPI-d8 alone than CsA treated groups $(3.3 \pm 1.1$ vs. $7.6 \pm 0.5$ hours; $P<0.05)$. A significant reduction in $C L_{\mathrm{TOT}}$ and $V d_{\mathrm{ss}}$ of CPI-d8 was observed with CsA coadministration $(1.3 \pm 0.9$ vs. $10.1 \pm 1.7 \mathrm{ml} / \mathrm{min}$ per kilogram and $0.24 \pm 0.13$ vs. $0.57 \pm 0.101 / \mathrm{kg}$, respectively) $(P<$ 0.01) (Table 2).

After oral administration of CPI-d8 alone, CPI-d8 was rapidly absorbed $\left(T_{\max }=1.5 \pm 1.3\right.$ hours), with a bioavailability of $3.2 \% \pm$ $1.7 \%$ (Fig. 1; Table 2). The maximum plasma concentration $\left(C_{\max }\right)$ and $\mathrm{AUC}_{0-24 \mathrm{~h}}$ of CPI-d8 in plasma were $1.1 \pm 0.5 \mathrm{nM}$ and $9.8 \pm 3.0$ $\mathrm{nM} \bullet \mathrm{h}$, respectively. Likewise, the coadministration of CsA increased CPI-d8 systemic exposure after oral CPI-d8 dosing, although with lower fold changes of $\mathrm{AUC}_{0-24 \mathrm{~h}}$ and $\mathrm{AUC}_{\mathrm{TOT}}$ (2.8- and 2.4-fold, respectively), compared with intravenous administration (Fig. 1; Table 2). Marked increases in CPI-d8 $C_{\max }$ were also observed after CsA administration, with fold change of approximately 2.2-fold $(P>0.05)$ (Fig. 1; Table 2). CsA administration may decrease CPI-d8 oral bioavailability versus the control, with bioavailability values of $0.8 \% \pm 0.6 \%$ and $3.2 \% \pm 1.7 \%$, respectively (Fig. 1; Table 2). However, the difference is not statistically significant $(P>0.05)$. The large interindividual variability potentially affected the statistical assessment.

Pharmacokinetics of CsA in Monkeys. The mean CsA blood concentration versus time profiles following the administration of a single oral dose of 4,20 , and $100 \mathrm{mg} / \mathrm{kg} \mathrm{CsA}$ to male cynomolgus monkeys are illustrated in Figure 2. Increase in blood Cmax after a single dose of CsA was nearly proportional to the dose increment between 4 and $100 \mathrm{mg} / \mathrm{kg}$ doses $(0.19 \pm 0.04$ and $3.8 \pm 2.3 \mu \mathrm{M}$, respectively), and it was more proportional to the dose increment between 4 and $20 \mathrm{mg} / \mathrm{kg}$ $(0.19 \pm 0.04$ and $2.5 \pm 1.6 \mu \mathrm{M}$, respectively) (Table 3$)$. In contrast, following a single oral administration of $4-100 \mathrm{mg} / \mathrm{kg} \mathrm{CsA}$, the increase in blood $\mathrm{AUC}_{0-24 \mathrm{~h}}$ was less proportional to the dose increment between
4 and $100 \mathrm{mg} / \mathrm{kg}(2.7 \pm 0.6$ and $26.6 \pm 4.1 \mu \mathrm{M} \cdot \mathrm{h}$, respectively) whereas approximately proportional to the dose increment between 4 and $20 \mathrm{mg} / \mathrm{kg}(2.7 \pm 0.6$ and $10.5 \pm 7.5 \mu \mathrm{M} \cdot \mathrm{h}$, respectively) (Table 3$)$. The oral exposure of CsA at $20 \mathrm{mg} / \mathrm{kg}$ was comparable to those reported in cynomolgus monkeys previously (Schuurman et al., 2001; Shen et al., 2015).

Effects of CsA Administration on Plasma CP Levels. Figure 3 shows the means \pm S.D. of plasma concentrations of exogenous and endogenous $\mathrm{CP}$ versus time for the entire study period, which includes vehicle, 4, 20, and $100 \mathrm{mg} / \mathrm{kg}$ CsA administration periods. Table 4 summarizes the exposures during the four periods. Compared with the vehicle control, CPI-d8 $\mathrm{AUC}_{0-24 \mathrm{~h}}$ was significantly increased $1.8 \pm$ 0.3-, $6.2 \pm 2.5-$, and $10.5 \pm 6.8$-fold by 4,20 , and $100 \mathrm{mg} / \mathrm{kg} \mathrm{CsA}$, respectively $(P<0.05)$. At all $\mathrm{CsA}$ dose levels, the recovery of unchanged CPI-d8 in urine was less than expected. The urinary recovery at $100 \mathrm{mg} / \mathrm{kg} \mathrm{CsA}$ was only approximately $40 \%$ of the dose. The poor recovery is likely due to the destruction and loss of $\mathrm{CP}$ by light during the urine collection using metabolic cages. As a result, the pharmacokinetic analysis of CPI-d8, CPI, and CPIII in urine was not performed. In contrast, plasma was prepared within 30 minutes of blood collection and stored in a freezer which was protected from light. The plasma concentrations of $\mathrm{CP}$ in this study were similar to those reported previously.

As with CPI-d8, the plasma levels of endogenous CPI and CPIII were measured in cynomolgus monkeys after increasing doses of CsA. In agreement, CPI and CPIII exhibited a marked dose-dependent increase in their plasma concentration-time profile (Fig. 3, B and C; Table 4). Compared with the vehicle control, the $\mathrm{AUC}_{0-24 \mathrm{~h}}$ and $C_{\max }$ of CPI and CPIII were increased 1.1-1.6-. 1.4-3.8-, and 4.5-6.9-fold at 4, 20, and $100 \mathrm{mg} / \mathrm{kg} \mathrm{CsA}$, respectively, although the increases were generally less proportional to the CsA dose increment (Fig. 5). In addition, the increase was only statistically significant at 20 and $100 \mathrm{mg} / \mathrm{kg} \mathrm{CsA}$ (Table 4).

Correlation between Increased Plasma Concentrations of Exogenous and Endogenous CP by CsA. To further study the potential of plasma concentrations of CPI and CPIII as an endogenous biomarker of OATP1B activity, the fold change in $\mathrm{CP} \mathrm{AUC}_{0-24 \mathrm{~h}}$ (AUCR) was correlated with that of CPI-d8 after increasing doses of CsA in this study. A good linear correlation $\left(R^{2}=0.920\right)$ between CPI AUCR and CPIII AUCR was observed (Fig. 4A), indicating comparable CsA dose response between endogenous plasma CPI and CPIII concentrations. More importantly, Figure 4, B and C, showed the 

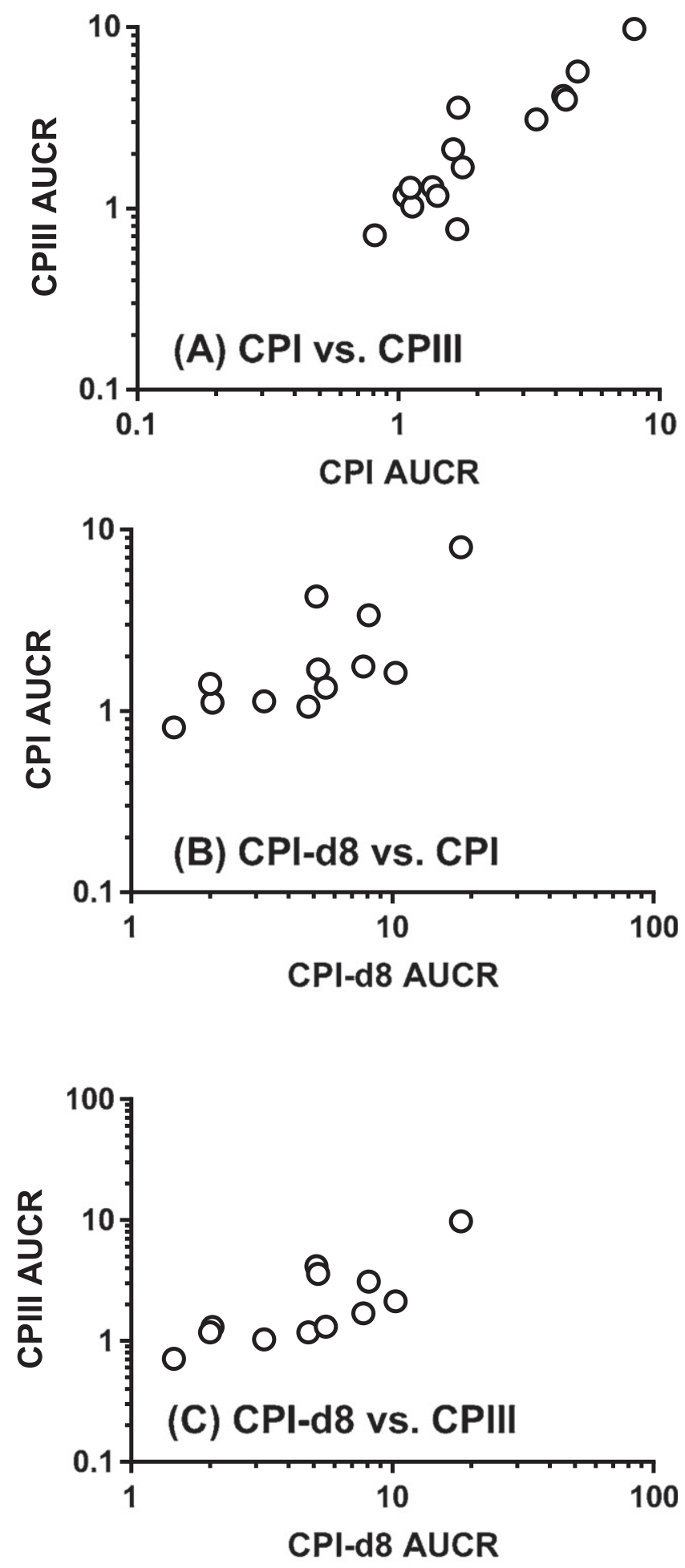

Fig. 4. Correlation between AUCRs from time of CsA administration up to the time of the last quantifiable concentration of CPI, CPIII, and CPI-d8 in cynomolgus monkeys.

presence of a significant and positive correlation using linear regression between CPI and CPI-d8 AUCR, and CPIII and CPI-d8 AUCR, respectively ( $R^{2}$ of 0.680 and 0.718 , respectively; $P<0.001$ ).

To assess CsA dose response, an effort was made to correlate $\mathrm{CP}$ AUCR with CsA $C_{\max }, \mathrm{AUC}_{0-24 \mathrm{~h}}$, and maximum unbound hepatic inlet
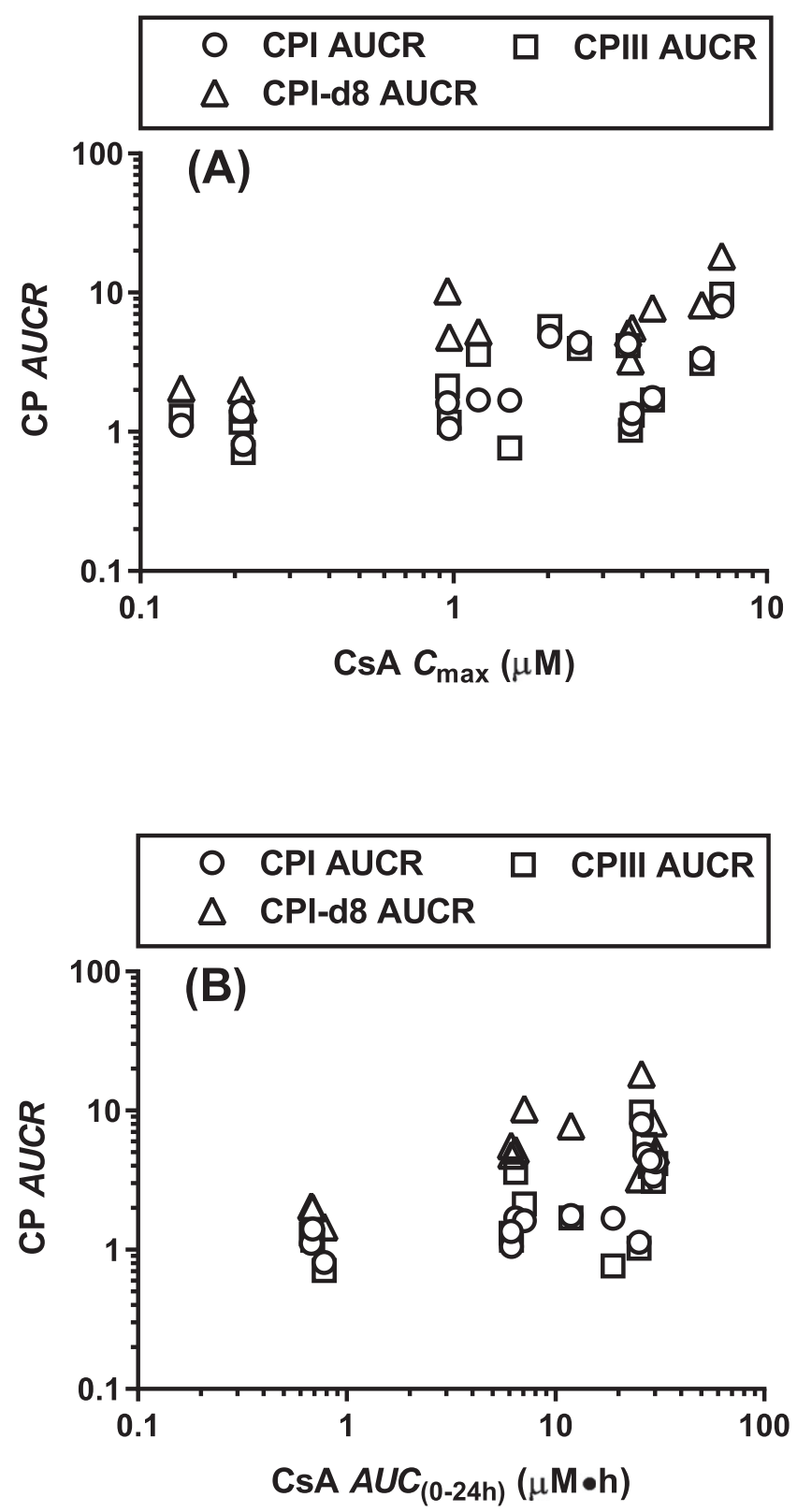

Fig. 5. Correlation between CsA $C_{\max }$ (A) or $\mathrm{AUC}_{0-24 \mathrm{~h}}(\mathrm{~B})$ and $\mathrm{AUCR}$ values of CPI, CPIII, and CPI-d8 after the administration of CsA in cynomolgus monkeys.

concentration $\left(I_{\text {in,max,u }}\right)$ that varied over a wide range in this study (Fig. 5; Table 5). A modest linear correlation between CsA $C_{\max }$ or $\mathrm{AUC}_{0-24} \mathrm{~h}$ and CP AUCR was observed $\left(R^{2}\right.$ of 0.523 and 0.447 , respectively; $P<0.05$ ). The results of in vitro-to-in vivo extrapolation analysis of DDI magnitude using a mechanistic static model are summarized in Table 5. The magnitude of AUCRs in the presence of 4, 20 and $100 \mathrm{mg} / \mathrm{kg}$ CsA are predicted to be 1.58, 4.06 and 15.4, respectively, using the cynomolgus monkey OATP1B $1 I C_{50}$ value of $0.28 \mu \mathrm{M}$ determined previously (Shen et al., 2013) (Table 5). Similarly, the AUCRs are 1.65, 4.42, and 17.1, respectively, using the reported CsA monkey OATP1B3 $I C_{50}$ of $0.25 \mu \mathrm{M}$ (Shen et al., 2013). The predicted AUCR values were within 1.6-fold of the observed data for CPI-d8 whereas the approach substantially overpredicted the observed AUCR of CPI and CPIII (1.5-3.9-fold), highlighting the difference of DDI magnitude between exogenous and endogenous coproporphyrins. This is likely due to altered efflux of endogenous coproporphyrins 
TABLE 5

Prediction of the DDI caused by CsA in cynomolgus monkeys using mechanistic static model

\begin{tabular}{|c|c|c|c|c|c|c|c|}
\hline \multirow{3}{*}{$\begin{array}{l}\text { Treatment } \\
\text { CPI }\end{array}$} & \multicolumn{4}{|c|}{ DDI prediction } & \multirow{3}{*}{$\begin{array}{l}\text { Observed CPI-d8 } \\
\text { fold change }\end{array}$} & \multirow{3}{*}{ Observed CPI fold change } & \multirow{3}{*}{$\begin{array}{l}\text { Observed CPIII } \\
\text { fold change }\end{array}$} \\
\hline & \multicolumn{2}{|c|}{ cOATP1B1 } & \multicolumn{2}{|c|}{ cOATP1B3 } & & & \\
\hline & $I C_{50}$ & AUCR & $I C_{50}$ & AUCR & & & \\
\hline & $\mu \mathrm{M}$ & & $\mu \mathrm{M}$ & & & & \\
\hline $4 \mathrm{mg} / \mathrm{kg} \mathrm{CsA}$ & 0.28 & 1.58 & 0.25 & 1.65 & 1.8 & 1.1 & 1.1 \\
\hline $20 \mathrm{mg} / \mathrm{kg} \mathrm{CsA}$ & 0.28 & 4.06 & 0.25 & 4.42 & 6.2 & 1.4 & 1.8 \\
\hline $100 \mathrm{mg} / \mathrm{kg} \mathrm{CsA}$ & 0.28 & 15.4 & 0.25 & 17.1 & 10.5 & 4.4 & 4.6 \\
\hline
\end{tabular}

from the hepatocytes and erythrocytes, the biosynthesis sites of CPI and CPIII, in the presence of CsA, which was not the case for exogenous CPI-d8.

Effects of PROB Administration on Plasma CP Levels. The systemic exposures of CPI and CPIII were determined after an i.v. dose of $2 \mathrm{mg} / \mathrm{kg}$ FSM alone, $40 \mathrm{mg} / \mathrm{kg}$ PROB alone, or PROB plus FSM in cynomolgus monkeys (Supplemental Fig. 2; Table 6). Compared with the FSM group, CPI AUC $\mathrm{AU}_{24 \mathrm{~h}}$ and $C_{\max }$ were decreased $11 \%-25 \%$ with PROB treatment either alone or coadministered with FSM $(P>0.05)$ (Table 6). Furthermore, CPIII $\mathrm{AUC}_{0-24 \mathrm{~h}}$ and $C_{\max }$ were increased $1.5 \pm 0.4$ - to $2.5 \pm 0.8$-fold by PROB; however, the change was not statistically significant (Table 6).

Effects of PYR Administration on Plasma CP Levels. Figure 6 illustrates the mean \pm S.D. of plasma concentrations of CPI and CPIII at 1,5 , and 24 hours after a single i.v. dose of $3.9 \mathrm{mg} / \mathrm{kg}$ MFM alone or MFM plus PYR (i.v., $0.5 \mathrm{mg} / \mathrm{kg}$ ). Plasma CP concentrations were comparable and not statistically different between MFM alone and PYR plus MFM periods, indicating no major effect of PYR on CP.

Biodistribution of $\left[{ }^{3} \mathbf{H}\right] \mathbf{C P I}$ in Mice. The QWBA images and tissue concentrations of $\left[{ }^{3} \mathrm{H}\right] \mathrm{CPI}$ at 2 and 20 minutes, 3 , and 24 hours after intravenous injection into normal C57BL6 wild type mice is shown in Supplemental Fig. 3 and Table 7. As expected, the liver, kidney and intestine were the major sites of distribution of $\left[{ }^{3} \mathrm{H}\right] \mathrm{CPI}$ (Supplemental Fig. 3, A and B; Table 7). High levels were also found in the blood. These high activities are consistent with the known elimination routes of CPI (Shen et al., 2016a). High levels of radioactivity in the lung may be associated with $\left.{ }^{3} \mathrm{H}\right] \mathrm{CPI}$ in the blood in this highly perfused tissue and $\left[{ }^{3} \mathrm{H}\right] \mathrm{CPI}$ clears from the lung with a half-life similar to the plasma halflife (Table 7). The brain had relatively low radioactivity.

The radioactivity in blood after intravenous administration of $\left[{ }^{3} \mathrm{H}\right] \mathrm{CPI}$ in control and RIF-treated mice decayed rapidly (Table 7). However, the blood terminal $\mathrm{T}_{1 / 2}$ of $\left.{ }^{3} \mathrm{H}\right] \mathrm{CPI}$ appeared to be affected by RIF, as the blood concentration of $\left[{ }^{3} \mathrm{H}\right] \mathrm{CPI}$ at 20 minutes were markedly increased in the presence of RIF (300 vs. $110 \mathrm{nCi} / \mathrm{g}$ ). Consistently, RIF noticeably increased the distribution of $\left[{ }^{3} \mathrm{H}\right] \mathrm{CPI}$ radioactivity in the kidney (AUC: $681 \mathrm{vs} .154 \mathrm{nCi} \cdot \mathrm{h} / \mathrm{g}$ ) whereas it had less pronounced impact within the liver (AUC: 804 vs. $557 \mathrm{nCi} \cdot \mathrm{h} / \mathrm{g}$ ).

\section{Discussion}

The recent growing interest in the use of coproporphyrins as endogenous biomarkers of OATP1B activity has resulted in questions about its absorption, distribution, metabolism, and elimination properties. Another related, albeit unproven concern, is the enterohepatic circulation of CPs, which may also hypothetically preclude achieving an optimal prediction of OATP1B activity by using CPs. Furthermore, the in vivo sensitivity and selectivity of CPs as biomarkers of OATP1B have not been fully investigated. For these reasons, noncommercially available CPI-d8 and $\left[{ }^{3} \mathrm{H}\right] \mathrm{CPI}$ were prepared, and the pharmacokinetics and biodistribution of CPI-d8 and $\left[{ }^{3} \mathrm{H}\right] \mathrm{CPI}$ were profiled in cynomolgus monkeys and C57BL6 mice, respectively. Furthermore, the plasma CPs at different doses of CsA, an OATP1B inhibitor, were characterized in monkeys. We also evaluate the effects of the inhibitors of organic anion transporters (PROB) and organic cation transporters (PYR) on plasma $\mathrm{CP}$ levels in monkeys.

We employed cynomolgus monkeys for CPI pharmacokinetics and drug interaction analysis because the cynomolgus monkey model was recently used to examine OATP1B-mediated DDI and predict human in vivo intrinsic hepatic clearance from cynomolgus monkey and human hepatocyte uptake for OATP substrates (Shen et al., 2013; Takahashi et al., 2013; Chu et al., 2015; Thakare et al., 2017; De Bruyn et al., 2018; Ufuk et al., 2018). This is particularly important because the OATP1B amino acid sequence and transport activity are known to be highly similar between cynomolgus monkeys and humans (Shen et al., 2013). CPI-d8 displayed moderate $T_{1 / 2}$ and $V d_{\mathrm{ss}}$ in cynomolgus monkeys (7.6 \pm 0.5 and $0.57 \pm 0.10 \mathrm{l} / \mathrm{kg}$, respectively) (Fig. 1; Table 2). The $T_{1 / 2}$ is

TABLE 6

Mean systemic exposures of CP in cynomolgus monkeys after a single intravenous dose of $2 \mathrm{mg} / \mathrm{kg}$ FSM alone, PROB alone (i.v., $40 \mathrm{mg} / \mathrm{kg}$ ), and PROB with FSM

Data are presented as means \pm S.D. $(n=3)$. The pharmacokinetic parameters were determined as indicated under Materials and Methods. AUCR and $\mathrm{C}_{\mathrm{max}} \mathrm{R}$ of $\mathrm{CP}$ dosed with PROB alone and with FSM compared with FSM group. Statistics were conducted by one-way ANOVA followed by Dunnett's multiple comparison method.

\begin{tabular}{|c|c|c|c|c|}
\hline \multirow{2}{*}{ Analyte } & \multirow{2}{*}{ Pharmacokinetic parameters } & \multicolumn{3}{|c|}{ Intravenous PROB dose } \\
\hline & & FSM alone & PROB alone & FSM with PROB \\
\hline \multirow[t]{4}{*}{ CPI } & $\mathrm{AUC}_{0-24 \mathrm{~h}}(\mathrm{nM} \bullet \mathrm{h})$ & $3.8 \pm 1.1$ & $2.9 \pm 0.5$ & $3.3 \pm 1.1$ \\
\hline & AUCR & 1.0 & $0.78 \pm 0.09$ & $0.89 \pm 0.15$ \\
\hline & $C_{\max }(\mathrm{nM})$ & $0.78 \pm 0.26$ & $0.56 \pm 0.12$ & $0.64 \pm 0.26$ \\
\hline & $C_{\max } R$ & 1.0 & $0.75 \pm 0.13$ & $0.84 \pm 0.25$ \\
\hline \multirow[t]{4}{*}{ CPIII } & $\mathrm{AUC}_{0-7 \mathrm{~h}}(\mathrm{nM} \bullet \mathrm{h})$ & $0.76 \pm 0.22$ & $1.05 \pm 0.19$ & $1.35 \pm 0.50$ \\
\hline & AUCR & 1.0 & $1.5 \pm 0.4$ & $1.9 \pm 0.7$ \\
\hline & $C_{\max }(\mathrm{nM})$ & $0.14 \pm 0.04$ & $0.25 \pm 0.04 *$ & $0.34 \pm 0.11$ \\
\hline & $C_{\max } R$ & 1.0 & $1.9 \pm 0.5$ & $2.5 \pm 0.8$ \\
\hline
\end{tabular}

$C_{\max } \mathrm{R}$, fold change in $C_{\max }$

${ }^{*} P<0.05$ compared with the FSM group. 

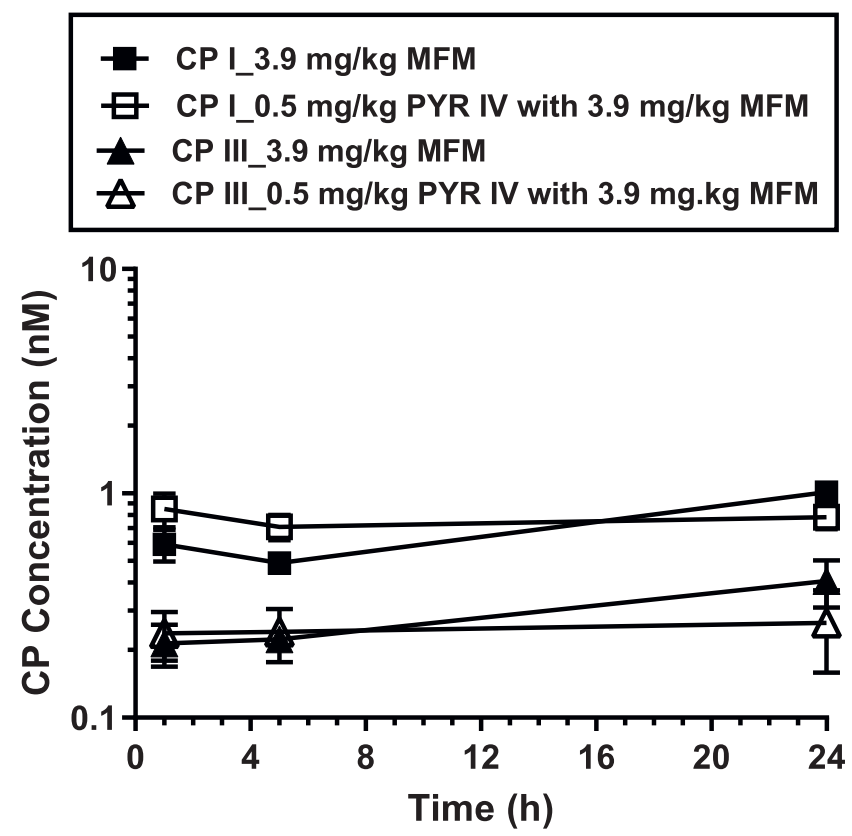

Fig. 6. Plasma concentrations of CPI and CPIII at 1, 5, and 24 hours after administration of a single intravenous dose of $3.9 \mathrm{mg} / \mathrm{kg}$ MFM (closed squares and triangles, respectively) and coadministration of intravenous dose of $0.5 \mathrm{mg} / \mathrm{kg}$ PYR and MFM (open squares and triangles, respectively. Data are expressed as means \pm S.D.

appropriate for an endogenous biomarker of drug metabolizing enzymes or transporters. For example, the rate of elimination of $4 \beta$-hydroxycholesterol, an endogenous marker of CYP3A4/5 activity in humans, is slow ( $T_{1 / 2} 17$ days), which limits its use to study rapid changes in CYP3A activity. In addition, we report for the first time that the absolute bioavailability of oral CPI $(0.2 \mathrm{mg} / \mathrm{kg}$ CPI-d8) is averaged $3.2 \% \pm$ $1.7 \%$. CsA (PO, $100 \mathrm{mg} / \mathrm{kg}$ ), a pan-inhibitor of intestinal multidrug resistance-associated protein 2, P-glycoprotein and breast cancer resistance protein, and hepatic OATP, had no significant effect on the oral absorption and bioavailability of CPI-d8 compared with the vehicle control although the mean bioavailability was decreased by CsA $(0.8 \% \pm 0.6 \%$ vs. $3.2 \% \pm 1.7 \%)(P>0.05)$ (Table 2$)$. These results are consistent with the in vitro human transporter phenotyping data. The studies from transporter transfected systems showed CPI was not a substrate for human intestinal transporters including P-glycoprotein, breast cancer resistance protein, or OATP2B1 although the substrate potential of CPI toward transporters may display a difference between cynomolgus monkeys and humans (Bednarczyk and Boiselle, 2016; Shen et al., 2017; Kunze et al., 2018a). It is worth noting that the enterohepatic circulation of CPI was reported in a clinical study performed several decades ago (Koskelo and Kekki, 1976). In these early studies, enterohepatic circulation was usually concluded by observation of a "secondary peak" in the time versus concentration curve after a single intravenous administration, but pertinent mechanism(s) explaining the secondary peak were not rigorously investigated. In fact, except for the report several decades ago, the enterohepatic circulation of CPI has not been reported. In addition, Takehara et al. (2019) have recently shown via bile duct cannulation data that CPI and CPIII did not undergo enterohepatic circulation in cynomolgus monkeys (Takehara et al., 2019). Plasma CPI and CPIII concentrations were not altered in bile duct-cannulated monkeys compared with normal animals (Takehara et al., 2019). In contrast, bile flow diversion markedly decreased the plasma level of bile acid-O-sulfates such as glycochenodeoxycholic acid 3-O-sulfate. The intestinal absorption of bile acids but not coproporphyrins plays an important role in their homeostasis (Takehara et al., 2019). Taken together, CPI does not undergo enterohepatic circulation in cynomolgus monkeys.

The mouse study shows the rapid and selective elimination of radiolabeled CPI via the liver and kidney. After intravenous injection of $\left[{ }^{3} \mathrm{H}\right] \mathrm{CPI}$ in mice, the liver, kidney, and intestinal tissues, had relatively high uptake and exposure, demonstrating the specificity of CPI for these elimination organs (Supplemental Fig. 3A; Table 7). The uptake in the lung at 2 minutes was comparable to that in the liver but then declined in parallel to the blood concentration, suggesting that lung exposure was due to the high blood volume in this tissue. Other tissues such as brain and muscle had relatively low values for $\left[{ }^{3} \mathrm{H}\right] \mathrm{CPI}$ concentration. The biodistribution of CPI in mice in the presence of RIF, a hepatic OATP inhibitor, differs considerably from that in the absence of the inhibitor (Supplemental Fig. 3; Table 7). The maximal distribution of $\left[{ }^{3} \mathrm{H}\right] \mathrm{CPI}$ to the intestine was $1350 \mathrm{nCi}\left[{ }^{3} \mathrm{H}\right] \mathrm{CPI} / \mathrm{g}$ (at 3 hours) in the coadministration group whereas $\left[{ }^{3} \mathrm{H}\right] \mathrm{CPI}$ was rapidly eliminated to the intestine in the absence of RIF (maximal distribution of $5850 \mathrm{nCi}\left[{ }^{3} \mathrm{H}\right] \mathrm{CPI} / \mathrm{g}$ at 20 minutes). In addition, the uptake of $\left[{ }^{3} \mathrm{H}\right] \mathrm{CPI}$ into the liver was inhibited by RIF (maximal uptake of 360 vs. $150 \mathrm{nCi}\left[{ }^{3} \mathrm{H}\right] \mathrm{CPI} / \mathrm{g}$ ). In contrast, the distribution of $\left[{ }^{3} \mathrm{H}\right] \mathrm{CPI}$ radioactivity in the kidney was increased by RIF (AUC: 681 vs. $154 \mathrm{nCi} \cdot \mathrm{h} / \mathrm{g}$ ). These results are consistent with the pattern of CPI excretion in rodent (Kaplowitz et al., 1972) and human bile and urine (Aziz and Watson, 1969; Mustajoki and Koskelo, 1976; Rocchi et al., 1984). It has been

TABLE 7

Tissue concentration of $\left[{ }^{3} \mathrm{H}\right] \mathrm{CPI}$ determined by QWBA in mice after a single intravenous dose of $0.04 \mathrm{mg} / \mathrm{kg}\left[{ }^{3} \mathrm{H}\right] \mathrm{CPI}(5 \mathrm{mCi} / \mathrm{kg})$ alone and $\left[{ }^{3} \mathrm{H}\right]$ CPI with RIF (PO, $100 \mathrm{mg} / \mathrm{kg})(n=8$ for each group and $n=2$ for each time point)

$\left[{ }^{3} \mathrm{H}\right] \mathrm{CPI}$ was administered intravenously 60 minutes after RIF administration (PO, $100 \mathrm{mg} / \mathrm{kg}$ ) in male C57BL6 mice. The QWBA was performed as indicated under Materials and Methods.

\begin{tabular}{|c|c|c|c|c|c|}
\hline \multirow{2}{*}{ Intravenous $\left[{ }^{3} \mathrm{H}\right] \mathrm{CPI}$ dose } & \multirow{2}{*}{ Tissue } & \multicolumn{4}{|c|}{ Concentration (nCi $\left[{ }^{3} \mathrm{H}\right] \mathrm{CPI} / \mathrm{g}$ ) } \\
\hline & & $2 \mathrm{~min}$ & $20 \mathrm{~min}$ & $3 \mathrm{~h}$ & $24 \mathrm{~h}$ \\
\hline \multirow{6}{*}[{}^{3}\mathrm{H}]{$\mathrm{CPI}$ alone } & Blood & 90 & 110 & 0 & 0 \\
\hline & Brain & 0 & 0 & 0 & 0 \\
\hline & Liver & 140 & 360 & 0 & 0 \\
\hline & Lung & 90 & 120 & 0 & 0 \\
\hline & Kidney & 1972 & 80 & 0 & 0 \\
\hline & Intestine & 0 & 5850 & 4110 & 0 \\
\hline \multirow[t]{6}{*}[{}^{3}\mathrm{H}]{$\mathrm{CPI}$ with RIF } & Blood & 150 & 300 & 0 & 0 \\
\hline & Brain & 0 & 0 & 0 & 0 \\
\hline & Liver & 80 & 150 & 50 & 0 \\
\hline & Lung & 250 & 210 & 0 & 0 \\
\hline & Kidney & 50 & 300 & 30 & 0 \\
\hline & Intestine & 10 & 20 & 1350 & 0 \\
\hline
\end{tabular}


demonstrated that approximately $70 \%-80 \%$ of the daily CPI is found in the bile whereas the remainder is excreted in the urine of healthy subjects. With impairment of hepatic excretory function by genetic mutation (i.e., Rotor syndrome) or chemical inhibitors (such as oral contraceptive agents, RIF, and CsA), there is an increase in the CPI excreted in urine (Koskelo et al., 1966; Ben-Ezzer et al., 1971; Wolkoff et al., 1976; Shimizu et al., 1981; Lai et al., 2016; Shen et al., 2018b; Yee et al., 2019). This change in the pattern of CPI excretion is consistent with the observation of $\left[{ }^{3} \mathrm{H}\right] \mathrm{CPI}$ in the mice pretreated with RIF in this study (Supplemental Fig. 3; Table 7). Of note, the recovery of unchanged CPI-d8 in urine was less than expected in cynomolgus monkeys. The urinary recovery following i.v. administration of $0.1 \mathrm{mg} / \mathrm{kg}$ CPI-d8 alone and in combination with $100 \mathrm{mg} / \mathrm{kg}$ CsA were $4.2 \%$ and $40 \%$ of the dose, respectively. The poor recovery may be due to the destruction of $\mathrm{CP}$ by light during the urine collection using metabolic cages. In contrast, plasma was prepared within 30 minutes of blood collection and stored in a freezer, protected from light. The plasma levels of CPI and CPIII are similar to those reported before.

To assess the CsA dose-dependent response, CsA Neoral microemulsion was administered to cynomolgus monkeys at three dose levels of 4, 20, and $100 \mathrm{mg} / \mathrm{kg}$ along with CPI-d8. As shown in Fig. 2A and Table 3, mean total blood $C_{\max }$ values of $0.19,2.5$, and $3.8 \mu \mathrm{M}$ and $\mathrm{AUC}_{0-24 \mathrm{~h}}$ values of $2.7,10.5$, and $26.6 \mu \mathrm{M} \cdot \mathrm{h}$ were found at 4,20 , and $100 \mathrm{mg} / \mathrm{kg} \mathrm{CsA}$, respectively. These pharmacokinetic parameters are similar to the nonhuman primate data reported previously (Schuurman et al., 2001; Shen et al., 2015). Apparently, the increases in $C_{\max }$ and $\mathrm{AUC}_{0-24 \mathrm{~h}}$ were generally proportional to dose between 4 and $20 \mathrm{mg} / \mathrm{kg}$, whereas those were less than dose proportional between 20 and $100 \mathrm{mg} / \mathrm{kg}$ (Fig. 2, B and C). Despite the nonlinearity, there was a modest linear correlation between CsA blood $C_{\max }$ or $\mathrm{AUC}_{0-24 \mathrm{~h}}$ and CP AUCR ( $R^{2}$ of 0.523 and 0.447 , respectively; $P<0.05$ ) (Fig. 5). A clear CsA dose-dependent increase in the AUCRs of CPI-d8 (1.8, 6.2, and 10.5), CPI (1.1, 1.4, and 4.4), and CPIII (1.1, 1.8, and 4.6) were observed (Table 4). These CsA dose response results indicate that CPI and CPIII are sensitive OATP1B endogenous biomarkers. However, the magnitude of the AUCRs of CPI-d8 in the presence of 4, 20, and $100 \mathrm{mg} / \mathrm{kg} \mathrm{CsA}$ are greater than those of CPI and CPIII (Table 5). This is likely due to the reduced efflux of endogenous CPs but not exogenous CPI-d8 from the hepatocytes and erythrocytes. It has been reported that CPI and CPIII are substrates of MRP3 (Kunze et al., 2018b). Bristol Myers Squibb studies also show that both CPI and CPIII are substrate of MRP4 (unpublished data).

To further study the selectivity of CPs as probes of OATP1B over OAT1, OAT3, OCT2, MATE1, and MATE2-K, we evaluated the effects of a renal organic anion transporter inhibitor PROB (i.v., $40 \mathrm{mg} / \mathrm{kg}$ ) and an organic cation transporter inhibitor PYR (i.v., $0.5 \mathrm{mg} / \mathrm{kg}$ ) on plasma CP levels in cynomolgus monkeys (Fig. 6; Supplemental Fig. 2). The plasma samples were obtained from our previous study, in which PROB increased the AUC of coadministered furosemide, a known substrate of OAT1 and OAT3, by 4.1-fold in same animals (Shen et al., 2018c). There were generally no statistically significant increases in plasma concentrations of CPI or CPIII observed even though mean CPIII exhibited increased $\mathrm{AUC}_{0-24 \mathrm{~h}}$ and $C_{\max }$ ratio by PROB (1.5-2.5-fold) (Table 6). This may be attributed to large interindividual variability in plasma CPIII levels in cynomolgus monkeys. In addition, it has been reported that oral administration of $30 \mathrm{mg} / \mathrm{kg}$ PROB increased plasma pitavastatin and rosuvastatin exposures by approximately 2- to 3-fold in cynomolgus monkeys through OATP1B inhibition (Kosa et al., 2018). Consistently, PROB significantly inhibited the uptake of pitavastatin and rosuvastatin in monkey hepatocytes (Kosa et al., 2018). When studying effect of PYR on $\mathrm{CP}$ exposure at the i.v. dose of $0.5 \mathrm{mg} / \mathrm{kg}$ in cynomolgus monkeys, no statistically significant increases in plasma concentrations and urinary excretion rate of CPI and CPIII were observed (Fig. 6). In contrast, our previous study showed that the intravenous pretreatment of the same animals with $0.5 \mathrm{mg} / \mathrm{kg}$ PYR increased the AUC by 2.2-fold compared with vehicle control (Shen et al., 2016b).

In conclusion, following a series of in vivo cynomolgus monkey and mouse studies, we demonstrated that CPI displayed limited oral absorption, a short half-life, and low exposure to tissues except for elimination organs. We also established that CPI and CPIII in plasma are sensitive and selective biomarkers reflecting OATP1B inhibition over OAT1/3 and OCT2-/MATE1/2-K inhibition in monkeys. Moreover, we have shown that OATP1B inhibition can alter the biodistribution and elimination of CPI. These results suggest that hepatic OATP transporters are major determinants of the disposition of CPI in cynomolgus monkeys and mice and CPI is a sensitive and selective endogenous biomarker of hepatic OATP inhibition.

\section{Authorship Contributions}

Participated in research design: Gan, Hong, Lai, Sinz, Shen.

Conducted experiments: Gu, Wang, Tian.

Contributed new reagents or analytic tools: Gu, Shen.

Performed data analysis: Gu, Wang, Gan, Lai, Shen.

Wrote or contributed to the writing of the manuscript: Gu, Wang, Gan, Lai, Sinz, Shen.

\section{References}

Awni WM, Kasiske BL, Heim-Duthoy K, and Rao KV (1989) Long-term cyclosporine pharmacokinetic changes in renal transplant recipients: effects of binding and metabolism. Clin Pharmacol Ther 45:41-48.

Aziz MA and Watson CJ (1969) An analysis of the porphyrins of normal and cirrhotic human liver and normal bile. Clin Chim Acta 26:525-531.

Barnett S, Ogungbenro K, Ménochet K, Shen H, Lai Y, Humphreys WG, and Galetin A (2018) Gaining mechanistic insight into coproporphyrin I as endogenous biomarker for OATP1Bmediated drug-drug interactions using population pharmacokinetic modeling and simulation. Clin Pharmacol Ther 104:564-574.

Bednarczyk D and Boiselle C (2016) Organic anion transporting polypeptide (OATP)-mediated transport of coproporphyrins I and III. Xenobiotica 46:457-466.

Ben-Ezzer J, Rimington C, Shani M, Seligsohn U, Sheba C, and Szeinberg A (1971) Abnormal excretion of the isomers of urinary coproporphyrin by patients with Dubin-Johnson syndrome in Israel. Clin Sci 40:17-30.

Cheung KWK, Yoshida K, Cheeti S, Chen B, Morley R, Chan IT, Sahasranaman S, and Liu L (2019) GDC-0810 pharmacokinetics and transporter-mediated drug interaction evaluation with an endogenous biomarker in the first-in-human, dose escalation study. Drug Metab Dispos 47: 966-973.

Chu X, Chan GH, and Evers R (2017) Identification of endogenous biomarkers to predict the propensity of drug candidates to cause hepatic or renal transporter-mediated drug-drug interactions. J Pharm Sci 106:2357-2367.

Chu X, Liao M, Shen H, Yoshida K, Zur AA, Arya V, Galetin A, Giacomini KM, Hanna I, Kusuhara H, et al.; International Transporter Consortium (2018) Clinical probes and endogenous biomarkers as substrates for transporter drug-drug interaction evaluation: perspectives from the international transporter consortium. Clin Pharmacol Ther 104:836-864.

Chu X, Shih SJ, Shaw R, Hentze H, Chan GH, Owens K, Wang S, Cai X, Newton D, Castro-Perez $\mathrm{J}$, et al. (2015) Evaluation of cynomolgus monkeys for the identification of endogenous biomarkers for hepatic transporter inhibition and as a translatable model to predict pharmacokinetic interactions with statins in humans. Drug Metab Dispos 43:851-863.

Davies B and Morris T (1993) Physiological parameters in laboratory animals and humans. Pharm Res 10:1093-1095.

De Bruyn T, Ufuk A, Cantrill C, Kosa RE, Bi YA, Niosi M, Modi S, Rodrigues AD, Tremaine LM, Varma MVS, et al. (2018) Predicting human clearance of organic anion transporting polypeptide substrates using cynomolgus monkey: in vitro-in vivo scaling of hepatic uptake clearance. Drug Metab Dispos 46:989-1000.

Drewe J, Beglinger C, and Kissel T (1992) The absorption site of cyclosporin in the human gastrointestinal tract. Br J Clin Pharmacol 33:39-43.

Kandoussi H, Zeng J, Shah K, Paterson P, Santockyte R, Kadiyala P, Shen H, Shipkova P, Langish R, Burrrell R, et al. (2018) UHPLC-MS/MS bioanalysis of human plasma coproporphyrins as potential biomarkers for organic anion-transporting polypeptide-mediated drug interactions. Bioanalysis 10:633-644.

Kaplowitz N, Javitt N, and Kappas A (1972) Coproporphyrin I and 3 excretion in bile and urine. J Clin Invest 51:2895-2899.

König J, Seithel A, Gradhand U, and Fromm MF (2006) Pharmacogenomics of human OATP transporters. Naunyn Schmiedebergs Arch Pharmacol 372:432-443.

Kosa RE, Lazzaro S, Bi YA, Tierney B, Gates D, Modi S, Costales C, Rodrigues AD, Tremaine LM, and Varma MV (2018) Simultaneous assessment of transporter-mediated drug-drug interactions using a probe drug cocktail in cynomolgus monkey. Drug Metab Dispos 46:1179-1189. Koskelo P, Eisalo A, and Toivonen I (1966) Urinary excretion of porphyrin precursors and coproporphyrin in healthy females on oral contraceptives. BMJ 1:652-654.

Koskelo P and Kekki M (1976) Multicompartment analysis of 14C-labelled coproporphyrin and uroporphyrin kinetics in human beings. Ann Clin Res 8 (Suppl 17):198-202. 
Kunze A, Ediage EN, Dillen L, Monshouwer M, and Snoeys J (2018a) Clinical investigation of coproporphyrins as sensitive biomarkers to predict mild to strong OATP1B-mediated drug-drug interactions. Clin Pharmacokinet 57:1559-1570.

Kunze A, Ediage EN, Dillen L, Monshouwer M, and Snoeys J (2018b) Clinical investigation of coproporphyrins as sensitive biomarkers to predict mild to strong $\mathrm{OATP}_{1} \mathrm{~B}$-mediated drug-drug interactions. Clin Pharmacokinet 57:1559-1570.

Lai Y, Mandlekar S, Shen H, Holenarsipur VK, Langish R, Rajanna P, Murugesan S, Gaud N, Selvam S, Date O, et al. (2016) Coproporphyrins in plasma and urine can Be appropriate clinical biomarkers to recapitulate drug-drug interactions mediated by organic anion transporting polypeptide inhibition. J Pharmacol Exp Ther 358:397-404.

Link E, Parish S, Armitage J, Bowman L, Heath S, Matsuda F, Gut I, Lathrop M, and Collins R SEARCH Collaborative Group (2008) SLCO1B1 variants and statin-induced myopathya genomewide study. $N$ Engl J Med 359:789-799.

Liu L, Cheeti S, Yoshida K, Choo E, Chen E, Chen B, Gates M, Singel S, Morley R, Ware J, et al. (2018) Effect of OATP1B1/1B3 inhibitor GDC-0810 on the pharmacokinetics of pravastatin and coproporphyrin I/III in healthy female subjects. J Clin Pharmacol 58:1427-1435.

Mariappan TT, Shen H, and Marathe P (2017) Endogenous biomarkers to assess drug-drug interactions by drug transporters and enzymes. Curr Drug Metab 18:757-768.

Marzolini C, Tirona RG, and Kim RB (2004) Pharmacogenomics of the OATP and OAT families. Pharmacogenomics 5:273-282.

Mueller EA, Kovarik JM, van Bree JB, Tetzloff W, Grevel J, and Kutz K (1994) Improved dose linearity of cyclosporine pharmacokinetics from a microemulsion formulation. Pharm Res 11: 301-304.

Müller F, Sharma A, König J, and Fromm MF (2018) Biomarkers for in vivo assessment of transporter function. Pharmacol Rev 70:246-277.

Mustajoki P and Koskelo P (1976) Hereditary hepatic porphyrias in Finland. Acta Med Scand 200 171-178.

Rocchi E, Balli F, Gibertini P, Trenti T, Pietrangelo A, Cassanelli M, Frigieri G, and Ventura E (1984) Coproporphyrin excretion in healthy newborn babies. J Pediatr Gastroenterol Nutr 3 : $402-407$.

Rodrigues AD, Taskar KS, Kusuhara H, and Sugiyama Y (2018) Endogenous probes for drug transporters: balancing vision with reality. Clin Pharmacol Ther 103:434-448.

Schuurman HJ, Slingerland W, Mennninger K, Ossevoort M, Hengy JC, Dorobek B, Vonderscher J, Ringers J, Odeh M, and Jonker M (2001) Pharmacokinetics of cyclosporine in monkeys after oral and intramuscular administration: relation to efficacy in kidney allografting. Transpl Int 14: $320-328$.

Shen H (2018) A pharmaceutical industry perspective on transporter and CYP-mediated drug-drug interactions: kidney transporter biomarkers. Bioanalysis 10:625-631.

Shen H, Chen W, Drexler DM, Mandlekar S, Holenarsipur VK, Shields EE, Langish R, Sidik K, Gan J, Humphreys WG, et al. (2017) Comparative evaluation of plasma bile acids, dehydroepiandrosterone sulfate, hexadecanedioate, and tetradecanedioate with coproporphyrins I and III as markers of OATP inhibition in healthy subjects. Drug Metab Dispos 45:908-919.

Shen H, Christopher L, Lai Y, Gong J, Kandoussi H, Garonzik S, Perera V, Garimella T, and Humphreys WG (2018a) Further studies to support the use of coproporphyrin I and III as novel clinical biomarkers for evaluating the potential for organic anion transporting polypeptide 1B1 and OATP1B3 inhibition. Drug Metab Dispos 46:1075-1082.

Shen H, Christopher L, Lai Y, Gong J, Kandoussi H, Garonzik S, Perera V, Garimella T, and Humphreys WG (2018b) Further studies to support the use of coproporphyrin I and III as novel clinical biomarkers for evaluating the potential for organic anion transporting polypeptide 1B1 and OATP1B3 inhibition. Drug Metab Dispos 46:1075-1082.

Shen H, Dai J, Liu T, Cheng Y, Chen W, Freeden C, Zhang Y, Humphreys WG, Marathe P, and Lai Y (2016a) Coproporphyrins I and III as functional markers of OATP1B activity: in vitro and in vivo evaluation in preclinical species. J Pharmacol Exp Ther 357:382-393.

Shen H, Liu T, Jiang H, Titsch C, Taylor K, Kandoussi H, Qiu X, Chen C, Sukrutharaj S, Kuit K et al. (2016b) Cynomolgus monkey as a clinically relevant model to study transport involving renal organic cation transporters: in vitro and in vivo evaluation. Drug Metab Dispos 44 238-249.

Shen H, Nelson DM, Oliveira RV, Zhang Y, Mcnaney CA, Gu X, Chen W, Su C, Reily MD, Shipkova PA, et al (2018c) Discovery and validation of pyridoxic acid and homovanillic acid as novel endogenous plasma biomarkers of organic anion transporter (OAT) 1 and OAT3 in cynomolgus monkeys. Drug Metab Dispos 46:178-188.

Shen H, Su H, Liu T, Yao M, Mintier G, Li L, Fancher RM, Iyer R, Marathe P, Lai Y, et al. (2015) Evaluation of rosuvastatin as an organic anion transporting polypeptide (OATP) probe substrate: in vitro transport and in vivo disposition in cynomolgus monkeys. J Pharmacol Exp Ther 353: 380-391.

Shen H, Wang L, Chen W, Menard K, Hong Y, Tian Y, Bonacorsi SJ, Humphreys WG, Lee FY, and Gan J (2016c) Tissue distribution and tumor uptake of folate receptor-targeted epothilone folate conjugate, BMS-753493, in CD2F1 mice after systemic administration. Acta Pharm Sin B 6:460-467.

Shen H, Yang Z, Mintier G, Han YH, Chen C, Balimane P, Jemal M, Zhao W, Zhang R, Kallipatti $\mathrm{S}$, et al. (2013) Cynomolgus monkey as a potential model to assess drug interactions involving hepatic organic anion transporting polypeptides: in vitro, in vivo, and in vitro-to-in vivo extrapolation. J Pharmacol Exp Ther 344:673-685.

Shimizu Y, Naruto H, Ida S, and Kohakura M (1981) Urinary coproporphyrin isomers in Rotor's syndrome: a study in eight families. Hepatology 1:173-178.

Takahashi T, Ohtsuka T, Uno Y, Utoh M, Yamazaki H, and Kume T (2016) Pre-incubation with cyclosporine A potentiates its inhibitory effects on pitavastatin uptake mediated by recombinantly expressed cynomolgus monkey hepatic organic anion transporting polypeptide. Biopharm Drug Dispos 37:479-490.

Takahashi T, Ohtsuka T, Yoshikawa T, Tatekawa I, Uno Y, Utoh M, Yamazaki H, and Kume T (2013) Pitavastatin as an in vivo probe for studying hepatic organic anion transporting polypeptide-mediated drug-drug interactions in cynomolgus monkeys. Drug Metab Dispos 41: $1875-1882$.

Takahashi T, Uno Y, Yamazaki H, and Kume T (2019) Functional characterization for polymorphic organic anion transporting polypeptides (OATP/SLCO1B1, 1B3, 2B1) of monkeys recombinantly expressed with various OATP probes. Biopharm Drug Dispos 40:62-69.

Takehara I, Watanabe N, Mori D, Ando O, and Kusuhara H (2019) Effect of rifampicin on the plasma concentrations of bile acid-O-sulfates in monkeys and human liver-transplanted chimeric mice with or without bile flow diversion. J Pharm Sci 108:2756-2764

Takehara I, Yoshikado T, Ishigame K, Mori D, Furihata KI, Watanabe N, Ando O, Maeda K, Sugiyama Y, and Kusuhara H (2018) Comparative study of the dose-dependence of OATP1B inhibition by rifampicin using probe drugs and endogenous substrates in healthy volunteers. Pharm Res 35:138.

Thakare R, Gao H, Kosa RE, Bi YA, Varma MVS, Cerny MA, Sharma R, Kuhn M, Huang B, Liu $\mathrm{Y}$, et al. (2017) Leveraging of rifampicin-dosed cynomolgus monkeys to identify bile acid 3-Osulfate conjugates as potential novel biomarkers for organic anion-transporting polypeptides. Drug Metab Dispos 45:721-733.

Tomita Y, Maeda K, and Sugiyama Y (2013) Ethnic variability in the plasma exposures of OATP1B1 substrates such as HMG-CoA reductase inhibitors: a kinetic consideration of its mechanism. Clin Pharmacol Ther 94:37-51.

Ufuk A, Kosa RE, Gao H, Bi YA, Modi S, Gates D, Rodrigues AD, Tremaine LM, Varma MVS, Houston JB, et al. (2018) In vitro-in vivo extrapolation of OATP1B-mediated drug-drug interactions in cynomolgus monkey. J Pharmacol Exp Ther 365:688-699.

Wang L, Prasad B, Salphati L, Chu X, Gupta A, Hop CE, Evers R, and Unadkat JD (2015) Interspecies variability in expression of hepatobiliary transporters across human, dog, monkey, and rat as determined by quantitative proteomics. Drug Metab Dispos 43:367-374.

Wilson J, Grant PJ, Davies JA, Boothby M, Gaffney PJ, and Prentice CR (1988) The relationship between plasma vasopressin and changes in coagulation and fibrinolysis during hip surgery. Thromb Res 51:439-445.

Wolkoff AW, Wolpert E, Pascasio FN, and Arias IM (1976) Rotor's syndrome. A distinct inheritable pathophysiologic entity. Am J Med 60:173-179.

Yee SW, Giacomini MM, Shen H, Humphreys WG, Horng H, Brian W, Lai Y, Kroetz DL, and Giacomini KM (2019) Organic anion transporter polypeptide 1B1 polymorphism modulates the extent of drug-drug interaction and associated biomarker levels in healthy volunteers. Clin Transl Sci 12:388-399.

Yoshida K, Guo C, and Sane R (2018) Quantitative prediction of OATP-mediated drug-drug interactions with model-based analysis of endogenous biomarker kinetics. CPT Pharmacometrics Syst Pharmacol 7:517-524.

Yoshikado T, Toshimoto K, Maeda K, Kusuhara H, Kimoto E, Rodrigues AD, Chiba K, and Sugiyama Y (2018) PBPK modeling of coproporphyrin I as an endogenous biomarker for drug interactions involving inhibition of hepatic OATP1B1 and OATP1B3. CPT Pharmacometrics Syst Pharmacol 7:739-747.

Yu J, Petrie ID, Levy RH, and Ragueneau-Majlessi I (2019) Mechanisms and clinical significance of pharmacokinetic-based drug-drug interactions with drugs approved by the U.S. Food and Drug Administration in 2017. Drug Metab Dispos 47:135-144.

Zhang Y, Panfen E, Fancher M, Sinz M, Marathe P, and Shen H (2019) Dissecting the contribution of OATP1B1 to hepatic uptake of statins using the OATP1B1 selective inhibitor estropipate. Mol Pharm 16:2342-2353.

Address correspondence to: Dr. Hong Shen, The Department of Metabolism and Pharmacokinetics (MAP), Bristol Myers Squibb Company, Route 206 and Province Line Rd., Princeton, NJ 08543. E-mail: hong.shen1@bms.com 